\title{
How does the terrestrial carbon exchange respond to inter-annual climatic variations? A quantification based on atmospheric $\mathrm{CO}_{2}$ data
}

\author{
Christian Rödenbeck $^{1}$, Sönke Zaehle ${ }^{1}$, Ralph Keeling ${ }^{2}$, and Martin Heimann ${ }^{1,3}$ \\ ${ }^{1}$ Max Planck Institute for Biogeochemistry, Jena, Germany \\ ${ }^{2}$ Scripps Institution of Oceanography, University of California, San Diego, USA \\ ${ }^{3}$ Institute for Atmospheric and Earth System Research (INAR), Faculty of Science, \\ University of Helsinki, Helsinki, Finland
}

Correspondence: Christian Rödenbeck (christian.roedenbeck@bgc-jena.mpg.de)

Received: 17 January 2018 - Discussion started: 22 January 2018

Revised: 5 April 2018 - Accepted: 11 April 2018 - Published: 24 April 2018

\begin{abstract}
The response of the terrestrial net ecosystem exchange (NEE) of $\mathrm{CO}_{2}$ to climate variations and trends may crucially determine the future climate trajectory. Here we directly quantify this response on inter-annual timescales by building a linear regression of inter-annual NEE anomalies against observed air temperature anomalies into an atmospheric inverse calculation based on long-term atmospheric $\mathrm{CO}_{2}$ observations. This allows us to estimate the sensitivity of NEE to inter-annual variations in temperature (seen as a climate proxy) resolved in space and with season. As this sensitivity comprises both direct temperature effects and the effects of other climate variables co-varying with temperature, we interpret it as "inter-annual climate sensitivity". We find distinct seasonal patterns of this sensitivity in the northern extratropics that are consistent with the expected seasonal responses of photosynthesis, respiration, and fire. Within uncertainties, these sensitivity patterns are consistent with independent inferences from eddy covariance data. On large spatial scales, northern extratropical and tropical interannual NEE variations inferred from the NEE- $T$ regression are very similar to the estimates of an atmospheric inversion with explicit inter-annual degrees of freedom. The results of this study offer a way to benchmark ecosystem process models in more detail than existing effective global climate sensitivities. The results can also be used to gap-fill or extrapolate observational records or to separate inter-annual variations from longer-term trends.
\end{abstract}

\section{Introduction}

About one-quarter of the carbon dioxide $\left(\mathrm{CO}_{2}\right)$ emitted to the atmosphere by human fossil fuel burning and cement manufacturing is currently taken up by the terrestrial biosphere (Le Quéré et al., 2016), thereby slowing down the rise of atmospheric $\mathrm{CO}_{2}$ levels and thus mitigating climate change. The magnitude of this terrestrial net ecosystem exchange (NEE) of $\mathrm{CO}_{2}$, however, is subject to substantial variability and trends, in large part as a response to variations and trends in climate. Due to this feedback loop, the response of NEE to climate may crucially determine the future climate trajectory (Friedlingstein et al., 2001), yet present-day coupled climate-carbon cycle models strongly disagree on its strength (Friedlingstein et al., 2014).

To reduce these uncertainties, observations of present-day year-to-year variations have been used as a constraint on the unobservable longer-term changes (Cox et al., 2013; Mystakidis et al., 2017) using the finding that these models show a close link between the climate-carbon cycle responses at year-to-year and centennial timescales. It cannot be known, however, to what extent this link indeed holds in reality (Mystakidis et al., 2017). While carbon cycle anomalies on the year-to-year timescale are clearly attributable to climate anomalies (through the variable occurrence of sunny vs. cloudy, warm vs. cold, and wet vs. dry days or periods), additional longer-term trends may arise as a response to growing nitrogen and $\mathrm{CO}_{2}$ fertilization, slow warming, expanding or shrinking vegetation, adaptation of ecosystems, shifts in 
species composition, or changing human agricultural practices and fire suppression. Some of these processes may also slowly change the strength of the short-term climatecarbon cycle responses over time. Moreover, both year-toyear and decadal to centennial carbon cycle changes are overlaid by the much larger periodic variability (day-night cycle, seasonal cycle). When using observations to constrain the climate-carbon cycle responses, it is therefore essential to employ observational records spanning time periods as long as possible to get statistically significant results and to separate the signals on seasonal, inter-annual, and decadal timescales (compare Rafelski et al., 2009).

Variability and trends of terrestrial carbon exchange have been observed through a variety of sustained measurements, including local measurements by eddy covariance towers measuring ecosystem fluxes (e.g. Baldocchi et al., 2001; Baldocchi, 2003) and indirect measurements by satellites recording changes in vegetation properties (e.g. Myeni et al., 1997). The longest observational records are the atmospheric $\mathrm{CO}_{2}$ measurements started in the late 1950s at Mauna Loa (Hawaii) and the South Pole by Keeling et al. (2005) and since then extended into a network of more than $100 \mathrm{CO}_{2}$ sampling locations worldwide. Based on the Mauna Loa long-term record considered to reflect global $\mathrm{CO}_{2}$ fluxes, a close link between the atmospheric $\mathrm{CO}_{2}$ growth rate and tropical temperature variations has been established (e.g. Wang et al., 2013). Using measurements from Barrow (Alaska) conceivably reflecting variations in boreal $\mathrm{CO}_{2}$ fluxes, similar relationships have been suggested for highlatitude ecosystems (e.g. Piao et al., 2017).

Extending these analyses, the aim of this study is to directly quantify the contributions of the different seasons and different climatic zones to the response of NEE to interannual climatic variations in order to obtain more processrelevant information. To this end, we combine a linear regression between NEE and climate anomalies with an "atmospheric inversion" (e.g. Newsam and Enting, 1988; Rayner et al., 1999; Rödenbeck et al., 2003; Baker et al., 2006; Peylin et al., 2013) which quantitatively disentangles the atmospheric $\mathrm{CO}_{2}$ signal into its contributions from the various regions and times of origin and allows us to make use of multiple long-term atmospheric $\mathrm{CO}_{2}$ records. In addition to the atmospheric data, eddy covariance data are used for independent verification.

\section{Method}

\subsection{The standard inversion}

As a starting point, we use the existing Bayesian atmospheric $\mathrm{CO}_{2}$ inversion implemented in the Jena CarboScope, run s85oc_v4.1s (update of Rödenbeck et al., 2003; Rödenbeck, 2005, see http://www.BGC-Jena.mpg.de/CarboScope/). It estimates spatially and temporally explicit $\mathrm{CO}_{2}$ fluxes be- tween the Earth's surface and the atmosphere based on atmospheric $\mathrm{CO}_{2}$ measurements from 23 stations (marked with * in Table 1) each of which spans the entire analysis period (chosen here to be 1985-2016 when more data are available; see Rödenbeck et al. (2018) for runs over 1957-2016). Using an atmospheric tracer transport model to simulate the atmospheric $\mathrm{CO}_{2}$ field that would arise from a given flux field, the inversion algorithm finds the flux field that leads to the closest match between observed and simulated $\mathrm{CO}_{2}$ mole fractions. In addition, the estimation is regularized by a priori constraints meant to suppress excessive spatial and highfrequency variability in the flux field. The a priori settings do not involve any information from biosphere process models. Fossil fuel fluxes are fixed to accounting-based values. In the particular run s85oc_v4.1s used here, ocean fluxes are fixed to estimates based on an interpolation of surface-ocean $p \mathrm{CO}_{2}$ data (Jena CarboScope run oc_v1.5). A more detailed technical specification, including references and highlighting changes with respect to earlier Jena CarboScope versions, is given in Appendix A.

For reference in Sect. 2.2 below, we mention here that this standard inversion calculation represents the total surface-toatmosphere $\mathrm{CO}_{2}$ flux $f$ as a decomposition,

$f=f_{\mathrm{NEE}, \mathrm{LT}}^{\mathrm{adj}}+f_{\mathrm{NEE}, \text { Seas }}^{\mathrm{adj}}+f_{\mathrm{NEE}, \mathrm{IAV}}^{\mathrm{adj}}+f_{\mathrm{Ocean}}^{\mathrm{fix}}+f_{\mathrm{Foss}}^{\mathrm{fix}}$,

into adjustable long-term mean terrestrial NEE $\left(f_{\mathrm{NEE}, \mathrm{LT}}^{\mathrm{adj}}\right)$, adjustable large-scale seasonal NEE anomalies $\left(f_{\mathrm{NEE}, \text { Seas }}^{\text {adj }}\right)$, adjustable inter-annual and shorter-term NEE anomalies $\left(f_{\mathrm{NEE}, \mathrm{IAV}}^{\mathrm{adj}}\right)$, the prescribed ocean fluxes $\left(f_{\text {Ocean }}^{\mathrm{fix}}\right)$, and the prescribed fossil fuel emissions $\left(f_{\text {Foss }}^{\text {fix }}\right)$. All these terms represent spatio-temporal fields.

This standard inversion will be used as a reference to compare the results of the NEE- $T$ inversion introduced below (Sect. 2.2) at large spatial scales. Further, we used its estimated NEE variations in preparatory tests to confirm that NEE- $T$ correlations actually exist and to determine the degrees of freedom needed to accommodate their spatiotemporal heterogeneity.

\subsection{The NEE-T inversion}

Compared to the standard inversion (run s85oc_v4.1s), the NEE- $T$ inversion (base run s04XocNEET_v4.1s) uses the same transport model and the same prescribed data-based $\mathrm{CO}_{2}$ fluxes of the ocean $\left(f_{\text {Ocean }}^{\mathrm{fix}}\right)$ and fossil fuel emissions $\left(f_{\text {Foss }}^{\text {fix }}\right)$. It also possesses the same adjustable degrees of freedom representing the long-term mean $\mathrm{CO}_{2}$ fluxes (term $\left.f_{\mathrm{NEE}, \mathrm{LT}}^{\text {adj }}\right)$ and its large-scale seasonality ( $f_{\mathrm{NEE}, \text { Seas }}^{\text {adj }}$ ).

The NEE- $T$ inversion differs only by replacing the explicitly time-dependent inter-annual NEE variations $\left(f_{\mathrm{NEE}, \mathrm{IAV}}^{\text {adj }}\right)$ with a linear NEE- $T$ regression term plus residual terms: 
Table 1. Atmospheric $\mathrm{CO}_{2}$ measurement stations used in the NEE$T$ inversion. The smaller set of stations used in the standard inversion is labelled with an asterisk. The eight parts individually omitted in sensitivity tests are separated by horizontal lines. Institutions are referenced as follows: AEMET: Gomez-Pelaez and Ramos (2011); BGC: Thompson et al. (2009); CSIRO: Francey et al. (2003); EC: Worthy (2003); FMI: Kilkki et al. (2015); HMS: Haszpra et al. (2001); IAFMS: Colombo and Santaguida (1994); JMA: Watanabe et al. (2000); LSCE: Monfray et al. (1996); NIES: Tohjima et al. (2008); NIPR: Morimoto et al. (2003); NOAA: Conway et al. (1994); Saitama: http://www.pref.saitama.lg.jp/b0508/cess-english/ index.html, last access: 17 January 2018; SAWS: Labuschagne et al. (2003); SIO: Keeling et al. (2005), Manning and Keeling (2006); UBA: Levin et al. (1995). Appended letters indicate the record type: (f): flask data, mostly weekly; (h): in situ data, mostly hourly; (d): in situ data, daytime only; (n): in situ data, night-time only.

\begin{tabular}{|c|c|c|c|c|}
\hline Code & $\begin{array}{r}\text { Latitude } \\
\left({ }^{\circ}\right)\end{array}$ & $\begin{array}{r}\text { Longitude } \\
\left({ }^{\circ}\right)\end{array}$ & $\begin{array}{r}\text { Height } \\
\text { (m a.s.l.) }\end{array}$ & Institution \\
\hline${ }^{*} \mathrm{CMN}$ & 44.18 & 10.70 & 2165 & IAFMS(n) \\
\hline *LJO & 32.87 & -117.25 & 15 & $\mathrm{SIO}(\mathrm{f})$ \\
\hline *ASC & -7.97 & -14.40 & 88 & NOAA(f) \\
\hline *BHD & -41.40 & 174.90 & 85 & $\mathrm{SIO}(\mathrm{f})$ \\
\hline *BRW & 71.32 & -156.61 & 13 & $\operatorname{NOAA}(h, f), \operatorname{SIO}(f)$ \\
\hline${ }^{*} \mathrm{CHR}$ & 1.70 & -157.16 & 3 & NOAA(f) \\
\hline *MID & 28.21 & -177.37 & 10 & NOAA(f) \\
\hline *MLO & 19.53 & -155.57 & 3417 & $\operatorname{NOAA}(h, f), \operatorname{SIO}(f)$ \\
\hline *SPO & -89.97 & -24.80 & 2816 & $\operatorname{NOAA}(h, f), \operatorname{SIO}(f)$ \\
\hline *SYO & -69.00 & 39.58 & 29 & $\mathrm{NIPR}(\mathrm{h})$ \\
\hline *KER & -29.03 & -177.15 & 2 & $\mathrm{SIO}(\mathrm{f})$ \\
\hline ESP & 49.38 & -126.54 & 27 & $\operatorname{CSIRO(f),~EC(f)~}$ \\
\hline MQA & -54.48 & 158.97 & 13 & $\operatorname{CSIRO}(\mathrm{f})$ \\
\hline RYO & 39.03 & 141.83 & 230 & JMA(d) \\
\hline MNM & 24.30 & 153.97 & 8 & $\mathrm{JMA}(\mathrm{d})$ \\
\hline MHD & 53.32 & -9.81 & 18 & NOAA(f) \\
\hline RPB & 13.16 & -59.43 & 19 & NOAA(f) \\
\hline UTA & 39.90 & -113.72 & 1332 & NOAA(f) \\
\hline HUN & 46.95 & 16.64 & 353 & $\operatorname{HMI}(\mathrm{d}), \operatorname{NOAA}(\mathrm{f})$ \\
\hline AZR & 38.76 & -27.23 & 23 & NOAA(f) \\
\hline HBA & -75.58 & -26.61 & 24 & NOAA(f) \\
\hline LEF & 45.93 & -90.26 & 791 & NOAA(f) \\
\hline SEY & -4.68 & 55.53 & 6 & NOAA(f) \\
\hline CPT & -34.35 & 18.48 & 230 & SAWS(d) \\
\hline PAL & 67.96 & 24.12 & 565 & $\operatorname{FMI}(\mathrm{d}), \operatorname{NOAA}(\mathrm{f})$ \\
\hline WLG & 36.28 & 100.91 & 3852 & $\mathrm{NOAA}(\mathrm{f})$ \\
\hline HAT & 24.05 & 123.80 & 10 & NIES(f) \\
\hline SBL & 43.93 & -60.01 & 5 & $E C(d, f)$ \\
\hline CRZ & -46.43 & 51.85 & 202 & NOAA(f) \\
\hline SGP & 36.71 & -97.49 & 348 & NOAA(f) \\
\hline SUM & 72.60 & -38.42 & 3214 & NOAA(f) \\
\hline WES & 54.93 & 8.32 & 12 & UBA(d) \\
\hline AVI & 17.75 & -64.75 & 5 & NOAA(f) \\
\hline EIC & -27.15 & -109.44 & 63 & NOAA(f) \\
\hline ICE & 63.40 & -20.29 & 124 & NOAA(f) \\
\hline TIK & 71.60 & 128.89 & 29 & NOAA(f) \\
\hline CVR & 16.86 & -24.87 & 10 & $\mathrm{BGC}(\mathrm{f})$ \\
\hline ZOT301 & 60.80 & 89.35 & 301 a.gr. & $\mathrm{BGC}(\mathrm{d}, \mathrm{f})$ \\
\hline POCN30 & 29.48 & -134.24 & 20 & NOAA(f) \\
\hline POCN20 & 19.69 & -132.68 & 20 & NOAA(f) \\
\hline POCN10 & 9.68 & -140.37 & 20 & NOAA(f) \\
\hline POC000 & 0.60 & -150.35 & 20 & NOAA(f) \\
\hline POCS10 & -10.02 & -3.61 & 20 & NOAA(f) \\
\hline POCS20 & -20.28 & 0.08 & 20 & NOAA(f) \\
\hline POCS30 & -29.68 & -0.04 & 20 & NOAA(f) \\
\hline
\end{tabular}

Table 1. Continued.

\begin{tabular}{|c|c|c|c|c|}
\hline Code & $\begin{array}{r}\text { Latitude } \\
\left({ }^{\circ}\right)\end{array}$ & $\begin{array}{r}\text { Longitude } \\
\left({ }^{\circ}\right)\end{array}$ & $\begin{array}{r}\text { Height } \\
\text { (m a.s.l.) }\end{array}$ & Institution \\
\hline *ALT & 82.47 & -62.42 & 202 & $\begin{array}{l}\operatorname{CSIRO}(f), E C(f), \\
\operatorname{NOAA}(f)\end{array}$ \\
\hline$* \mathrm{CBA}$ & 55.21 & -162.71 & 41 & $\operatorname{NOAA}(f), \operatorname{SIO}(f)$ \\
\hline${ }^{*} \mathrm{CGO}$ & -40.67 & 144.70 & 130 & $\operatorname{CSIRO}(f), \operatorname{NOAA}(f)$ \\
\hline *GMI & 13.39 & 144.66 & 6 & $\operatorname{NOAA}(f)$ \\
\hline$*$ IZO & 28.30 & -16.50 & 2367 & AEMET(h) \\
\hline * KEY & 25.67 & -80.18 & 4 & $\operatorname{NOAA}(\mathrm{f})$ \\
\hline *KUM & 19.51 & -154.82 & 22 & $\operatorname{NOAA}(f), \operatorname{SIO}(f)$ \\
\hline *NWR & 40.04 & -105.60 & 3526 & $\operatorname{NOAA}(f)$ \\
\hline *PSA & -64.92 & -64.00 & 12 & $\operatorname{NOAA}(f), \operatorname{SIO}(f)$ \\
\hline *SHM & 52.72 & 174.11 & 27 & $\operatorname{NOAA}(f)$ \\
\hline * SMO & -14.24 & -170.57 & 51 & $\operatorname{NOAA}(h, f), \operatorname{SIO}(f)$ \\
\hline *AMS & -37.80 & 77.54 & 55 & $\operatorname{LSCE}(\mathrm{d})$ \\
\hline CFA & -19.28 & 147.06 & 5 & CSIRO(f) \\
\hline MAA & -67.62 & 62.87 & 42 & $\operatorname{CSIRO}(f)$ \\
\hline SIS & 60.18 & -1.26 & 31 & $\operatorname{BGC}(f), \operatorname{CSIRO}(f)$ \\
\hline $\mathrm{SCH}$ & 47.92 & 7.92 & 1205 & $\mathrm{UBA}(\mathrm{n})$ \\
\hline BMW & 32.26 & -64.88 & 46 & NOAA(f) \\
\hline TAP & 36.72 & 126.12 & 21 & NOAA(f) \\
\hline UUM & 44.45 & 111.10 & 1012 & NOAA(f) \\
\hline ASK & 23.26 & 5.63 & 2715 & NOAA(f) \\
\hline TDF & -54.86 & -68.40 & 20 & NOAA(f) \\
\hline WIS & 30.41 & 34.92 & 319 & NOAA(f) \\
\hline ZEP & 78.91 & 11.89 & 479 & NOAA(f) \\
\hline FSD & 49.88 & -81.57 & 250 & $\mathrm{EC}(\mathrm{d})$ \\
\hline YON & 24.47 & 123.02 & 30 & $\mathrm{JMA}(\mathrm{d})$ \\
\hline $\mathrm{COI}$ & 43.15 & 145.50 & 45 & NIES(f) \\
\hline CYA & -66.28 & 110.52 & 55 & CSIRO(f) \\
\hline THD & 41.04 & -124.15 & 112 & NOAA(f) \\
\hline CIB & 41.81 & -4.93 & 848 & NOAA(f) \\
\hline KZD & 44.26 & 76.22 & 506 & NOAA(f) \\
\hline LLN & 23.47 & 120.87 & 2867 & NOAA(f) \\
\hline NAT & -5.66 & -35.22 & 53 & NOAA(f) \\
\hline NMB & -23.57 & 15.02 & 461 & NOAA(f) \\
\hline STM & 66.00 & 2.00 & 3 & NOAA(f) \\
\hline STP & 50.00 & 145.00 & 0 & $\mathrm{SIO}(\mathrm{f})$ \\
\hline BIK300 & 53.22 & 23.02 & 300 a.gr. & BGC(f) \\
\hline DDR & 36.00 & 139.18 & 840 & Saitama(n) \\
\hline $\mathrm{KEF}+\mathrm{RYF}$ & var. & var. & 0 & $\mathrm{JMA}(\mathrm{f})$ \\
\hline POCN25 & 25.20 & -133.99 & 20 & NOAA(f) \\
\hline POCN15 & 15.07 & -135.22 & 20 & $\operatorname{NOAA}(\mathrm{f})$ \\
\hline POCN05 & 4.80 & -145.11 & 20 & NOAA(f) \\
\hline POCS05 & -4.66 & -4.24 & 20 & NOAA(f) \\
\hline POCS15 & -14.72 & -0.15 & 20 & NOAA(f) \\
\hline POCS 25 & -25.01 & -0.17 & 20 & NOAA(f) \\
\hline
\end{tabular}

$T$ represents the monthly spatio-temporal field of air temperature taken from GISS (Hansen et al., 2010; GISTEMP Team, 2017) and interpolated to the spatial grid and daily time steps of the inversion (Appendix A). Its long-term mean, mean seasonal cycle, and decadal variations including linear trend $\left(T_{\mathrm{LT}+\text { Seas }+ \text { Deca+Trend }}\right)$ have been subtracted to only retain inter-annual (including non-seasonal month-to-month) anomalies. The scalar $w$ is a temporal weighting being 1 
within the analysis period 1985-2016 and zero outside; this ensures that the regression specifically refers to this period. The inter-annual temperature anomaly field is multiplied by unknown (i.e. adjustable by the inversion) scaling factors $\gamma_{\text {NEE- }}$ (the NEE- $T$ regression coefficients). These scaling factors are identical in each year of the inversion, but are allowed to vary smoothly both seasonally (with a correlation length of about 3 weeks such that $\gamma_{\text {NEE- } T}$ contains 13 independent degrees of freedom in time, repeated every year) and spatially (with correlation lengths of about $1600 \mathrm{~km}$ in the longitude direction and $800 \mathrm{~km}$ in the latitude direction, imposing a spatial smoothing on $\gamma_{\mathrm{NEE}-T}$ over the same spatial scales as the smoothing imposed on the inter-annual flux anomalies $f_{\mathrm{NEE}, \mathrm{IAV}}^{\mathrm{adj}}$ in the standard inversion). The need for seasonal and spatial resolution of $\gamma_{\mathrm{NEE}-T}$ has been inferred from an analysis of the standard inversion results (Sect. 2.1). The a priori spatial and temporal correlations are imposed on $\gamma_{\mathrm{NEE}-T}$ to prevent a localization of inverse adjustments in the vicinity of the atmospheric stations. In contrast to the standard inversion, however, where the a priori correlations lead to a smooth NEE field, the NEE result of the NEE- $T$ inversion still retains structure on the pixel and monthly scale from the temperature field. By having only 13 degrees of freedom in the time dimension, the introduction of the regression term also regularizes the inversion further compared with the explicit inter-annual term of the standard inversion, which has 796 degrees of freedom in the time dimension.

Equation (2) also contains adjustable residual terms (2nd line) to accommodate modes of variability from the atmospheric $\mathrm{CO}_{2}$ signals that cannot be explicitly represented by the regression term and might therefore be at risk of being aliased into spurious adjustments to $\gamma \mathrm{NEE}-T$.

- Outside the non-zero period 1985-2016 of the regression term, inter-annual NEE variations are represented by a standard inter-annual term $f_{\mathrm{NEE}, \mathrm{IAV}}^{\text {adj }}$ with weights $(1-w)$ opposite to those of the regression term.

- An adjustable linear trend $\left(f_{\mathrm{NEE}, \text { Trend }}^{\text {adj }}\right)$ is needed because trends have explicitly been removed from $T$. For every pixel, $f_{\mathrm{NEE} \text {,Trend }}^{\text {adj }}$ is proportional to the time difference $\Delta t$ since the beginning of the calculation period multiplied by an unknown trend parameter to be adjusted by the inversion (with zero prior). The trend parameters are correlated with each other in space with the same correlation length scale as the mean and interannual variability components of the standard inversion (i.e. as $f_{\mathrm{NEE}, \mathrm{LT}}^{\text {adj }}$ and $f_{\mathrm{NEE}, \mathrm{IAV}}^{\text {adj }}$ in Eq. 1).

- Further, as the NEE field from the standard inversion contains a strong increase in seasonal cycle amplitude in northern extratropical latitudes (described earlier in Graven et al., 2013, and Welp et al., 2016) which is expected to not (solely) arise from changes in the temperature seasonal cycle, we decoupled this mode of variabil- ity from the regression by adding it as an explicitly adjustable term $f_{\text {NEE,SCTrend }}^{\text {adj }}$. For each degree of freedom in the mean seasonality term $f_{\mathrm{NEE} \text {,Seas }}^{\text {adj }}$ in Eq. (1), the additional term $f_{\mathrm{NEE}, \mathrm{SCT} \text { rend }}^{\text {adj }}$ contains the same mode multiplied by $\Delta t$ and having its own adjustable strength parameter.

Any further residual modes of variability (including NEE variations related to variations in other environmental drivers uncorrelated to $T$ variations, non-linear responses, memory effects and internal ecosystem dynamics, errors in the employed $T$ field, errors in the a priori fixed ocean and fossil fuel terms, and effects of transport model errors) are not explicitly accounted for, as we lack sufficient a priori information to model them explicitly. To the extent that they are uncorrelated to $T$ variations, they will stay in the data residual of the inversion.

In contrast to the standard inversion using 23 stations with temporally homogeneous records over 1985-2016, the NEE$T$ inversion uses atmospheric data from 89 stations (Table 1) partially with shorter records but spatially covering the globe more evenly (including stations in northern Siberia and tropical America). While the standard inversion with explicitly time-dependent degrees of freedom can develop spurious NEE variations when stations pop in or out with time, the major inter-annual variability from the NEE- $T$ inversion comes from the regression term using its degrees of freedom $\left(\gamma_{\mathrm{NEE}-T}\right)$ repeatedly each year such that any data point influences all years of the calculation period simultaneously. Therefore, the NEE- $T$ inversion is not prone to spurious variations from a temporally changing station network.

\subsection{Sensitivity cases}

The algorithm uses several inputs carrying uncertainties and contains several parameters that are not well determined from a priori available information. Therefore, we also ran an ensemble of sensitivity cases. In each such sensitivity case, one of the uncertain elements of the algorithm is changed within ranges that may be considered as plausible as the base case: (1) longer spatial a priori correlations (2.4 times in the longitude direction and 1.6 times in the latitude direction) for $\gamma$ NEE-T, (2) 4 weeks (rather than 3 weeks) of temporal a priori correlation length scale for $\gamma_{\mathrm{NEE}-T}$, (3) halved a priori uncertainty range for $\gamma_{\mathrm{NEE}-T}$, (4) using ocean $\mathrm{CO}_{2}$ fluxes from the PlankTOM5 ocean biogeochemical process model (Buitenhuis et al., 2010) instead of the fluxes based on $p \mathrm{CO}_{2}$ measurements, (5) taking the gridded monthly land temperature field from Berkeley Earth (www.BerkeleyEarth.org, last access: 29 November 2017) instead of the GISS data set, and (6) using ERA-Interim meteorological fields (Dee et al., 2011) to drive the atmospheric transport model rather than NCEP meteorological fields.

Eight additional sensitivity cases have been run to demonstrate coherent information in the atmospheric data. The set 
Table 2. Eddy covariance sites used for comparison. For vegetation type abbreviations, see Fig. 3 (caption).

\begin{tabular}{lrrrl}
\hline FLUXNET-ID & Data period & Latitude $\left(^{\circ}\right)$ & Longitude $\left(^{\circ}\right)$ & Vegetation type \\
\hline AU-How & $2001-2014$ & -12.4943 & 131.1523 & WSA \\
AU-Tum & $2001-2014$ & -35.6566 & 148.1517 & EBF \\
BE-Bra & $1996-2014$ & 51.3092 & 4.5206 & MF \\
BE-Vie & $1996-2014$ & 50.3051 & 5.9981 & MF \\
CA-Man & $1994-2008$ & 55.8796 & -98.4808 & ENF \\
CH-Dav & $1997-2014$ & 46.8153 & 9.8559 & ENF \\
DE-Hai & $2000-2012$ & 51.0792 & 10.4530 & DBF \\
DE-Tha & $1996-2014$ & 50.9624 & 13.5652 & ENF \\
DK-Sor & $1996-2014$ & 55.4859 & 11.6446 & DBF \\
DK-ZaH & $2000-2014$ & 74.4732 & -20.5503 & GRA \\
FI-Hyy & $1996-2014$ & 61.8474 & 24.2948 & ENF \\
FI-Sod & $2001-2014$ & 67.3619 & 26.6378 & ENF \\
FR-LBr & $1996-2008$ & 44.7171 & -0.7693 & ENF \\
FR-Pue & $2000-2014$ & 43.7414 & 3.5958 & EBF \\
GF-Guy & $2004-2014$ & 5.2788 & -52.9249 & EBF \\
IT-Col & $1996-2014$ & 41.8494 & 13.5881 & DBF \\
IT-Cpz & $1997-2009$ & 41.7052 & 12.3761 & EBF \\
IT-Lav & $2003-2014$ & 45.9562 & 11.2813 & ENF \\
IT-Ren & $1998-2013$ & 46.5869 & 11.4337 & ENF \\
IT-SRo & $1999-2012$ & 43.7279 & 10.2844 & ENF \\
NL-Loo & $1996-2013$ & 52.1666 & 5.7436 & ENF \\
RU-Cok & $2003-2014$ & 70.8291 & 147.4943 & OSH \\
RU-Fyo & $1998-2014$ & 56.4615 & 32.9221 & ENF \\
US-Ha1 & $1991-2012$ & 42.5378 & -72.1715 & DBF \\
US-Los & $2000-2014$ & 46.0827 & -89.9792 & WET \\
US-Me2 & $2002-2014$ & 44.4523 & -121.5574 & ENF \\
US-MMS & $1999-2014$ & 39.3232 & -86.4131 & DBF \\
US-NR1 & $1998-2014$ & 40.0329 & -105.5464 & ENF \\
US-PFa & $1995-2014$ & 45.9459 & -90.2723 & MF \\
US-Syv & $2001-2014$ & 46.2420 & -89.3477 & MF \\
US-Ton & $2001-2014$ & 38.4316 & -120.9660 & WSA \\
US-UMB & $2000-2014$ & 45.5598 & -84.7138 & DBF \\
US-Var & $2000-2014$ & 38.4133 & -120.9507 & GRA \\
US-WCr & $1999-2014$ & 45.8059 & -90.0799 & DBF \\
ZA-Kru & $2000-2010$ & -25.0197 & 31.4969 & SAV \\
\hline
\end{tabular}

of 89 stations used in the base case was divided into eight mutually exclusive parts (Table 1). In each of the sensitivity cases, one of these parts was omitted, leaving sets of 73 to 82 remaining stations. With this construction, all eight runs still have global data coverage, but every station is absent in one of the runs. If the results depended on any particular station without being backed up by other stations, then the run omitting this station would show a substantial difference from the base run.

The range of results from this ensemble of sensitivity cases will be shown as an uncertainty range around the base case.

\subsection{Comparison to eddy covariance data}

For comparison of the estimated sensitivities $\gamma$ NEE-T against independent information, we also calculate NEE- $T$ relationships from eddy covariance (EC) measurements. We use NEE and co-measured air temperature records from the FLUXNET2015 data set (https://fluxnet.fluxdata.org, last access: 25 October 2017). EC sites (Table 2) have been chosen based on having long records (at least 12 years; two sites with 11 years were also included to have more ecosystem types represented). Crop sites have not been included because their flux variability may strongly depend on crop rotation.

We start from the half-hourly or hourly data sets (variables NEE_CUT_REF and TA_F_MDS, respectively). Records classified as "measured" (QC flag $=0)$ or "good quality gapfill" $(\mathrm{QC}$ flag $=1)$ in both variables are averaged over each month. Months with data coverage of $90 \%$ or less are discarded from the statistical analysis.

For each EC site and each month of the year, all available monthly $\mathrm{CO}_{2}$ flux values from the different years were regressed against the corresponding monthly air temperature values using ordinary least squares regression. 

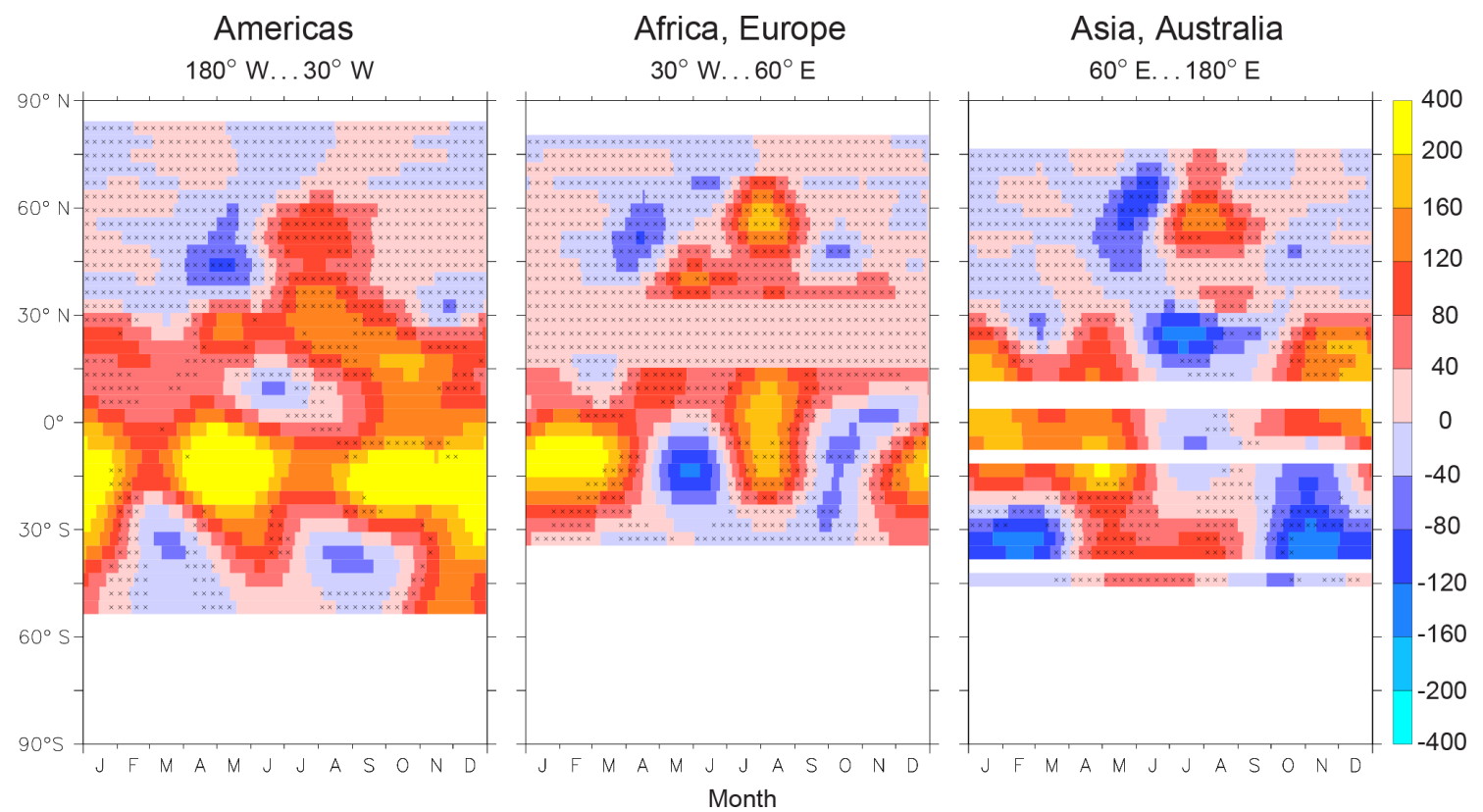

Figure 1. Inter-annual climate sensitivity $\gamma_{\mathrm{NEE}-T}$ in $\left(\mathrm{gC} \mathrm{m}^{-2} \mathrm{yr}^{-1}\right) \mathrm{K}^{-1}$ shown as Hovmöller diagrams: longitudinal averages of $\gamma_{\mathrm{NEE}-T}$ are plotted as colour over latitude (vertical) and month of the year (horizontal). The stippling indicates robustness: crosses mark values with absolute deviations $\leq 40\left(\mathrm{gC} \mathrm{m}^{-2} \mathrm{yr}^{-1}\right) \mathrm{K}^{-1}$ (one colour level) of all sensitivity cases from the base case.

This yields sensitivities as regression slopes $g_{\mathrm{NEE}-T}^{\mathrm{EC}}=$ $\Delta \mathrm{NEE}^{\mathrm{EC}} / \Delta T^{\mathrm{EC}}$. We also calculated the confidence interval of the slope for the confidence level $90 \%$, reflecting the uncertainty of $g_{\mathrm{NEE}-T}^{\mathrm{EC}}$ given the scatter of the monthly values around a linear relationship.

The sensitivities $\gamma_{\mathrm{NEE}-T}$ from the inversion and $g_{\mathrm{NEE}-T}^{\mathrm{EC}}$ from the explicit linear regression are not fully comparable mathematically because (i) the time period (and to some extent the frequency filtering) are different, and (ii) the explicit linear regression of the total NEE is not only influenced by the year-to-year variations but also by the ratio of NEE trend and temperature trend, while $\gamma$ NEE- $T$ has deliberately been made insensitive to the trend (Sect. 2.2). Therefore, we also calculated sensitivities $g_{\text {NEE- } T}^{\text {Inv }}$ from the total monthly mean non-fossil $\mathrm{CO}_{2}$ flux (i.e. including regression and residual terms of Eq. 2) and the employed temperature field of the inversions in the same way and subsampled at the same months as for the EC data. A perfect match between $g_{\mathrm{NEE}-T}^{\mathrm{EC}}$ and $g_{\mathrm{NEE}-T}^{\mathrm{Inv}}$ cannot be expected nevertheless because (iii) sensitivities from the inversion even at its smallest resolved scale - the pixel scale - represent a mixture of ecosystem types in unknown proportions, while the EC data represent a specific ecosystem type, (iv) NEE from the inversion includes the effects of disturbances such as fire, which are absent from the EC data, and (v) there may be local trends in the ecosystem behaviour observed by the EC data due to ageing or slow species shifts, which average out on the larger spatial scales seen by the atmospheric inversion.

\section{Results}

\subsection{How does the inter-annual climate sensitivity $\gamma$ NEE- $T$ vary in space and by season?}

As a starting point, we present the results of the NEE- $T$ inversion in terms of $\gamma_{\mathrm{NEE}-T}$, which is the local regression coefficient between inter-annual variations in NEE and temperature, resolved seasonally (Sect. 2.2). As $\gamma_{\mathrm{NEE}-T}$ not only reflects direct temperature responses but also responses to other environmental variables that co-vary with temperature (such as water availability, incoming solar radiation), we refer to it as inter-annual climate sensitivity.

Figure 1 presents the seasonal and spatial patterns of the inter-annual climate sensitivity as Hovmöller diagrams showing longitudinally averaged $\gamma$ NEE- $T$ with dependence on latitude and month of the year. The longitudinal average is taken separately over North and South America (left panel), Europe and Africa (middle panel), and Asia and Australia (right panel). This representation summarizes the essential variations of $\gamma_{\mathrm{NEE}-T}$, as it is found to be relatively uniform across longitude within the individual continents (not shown).

In essentially all northern extratropical land areas (north of about $35^{\circ} \mathrm{N}$ ), we estimate negative $\gamma$ NEE-T in spring (and to a lesser extent autumn), which is consistent with photosynthesis being temperature limited such that higher-thannormal temperatures lead to more negative NEE (i.e. largerthan-normal $\mathrm{CO}_{2}$ uptake) and vice versa. Warmer conditions tend to coincide with higher incoming solar radiation in May 

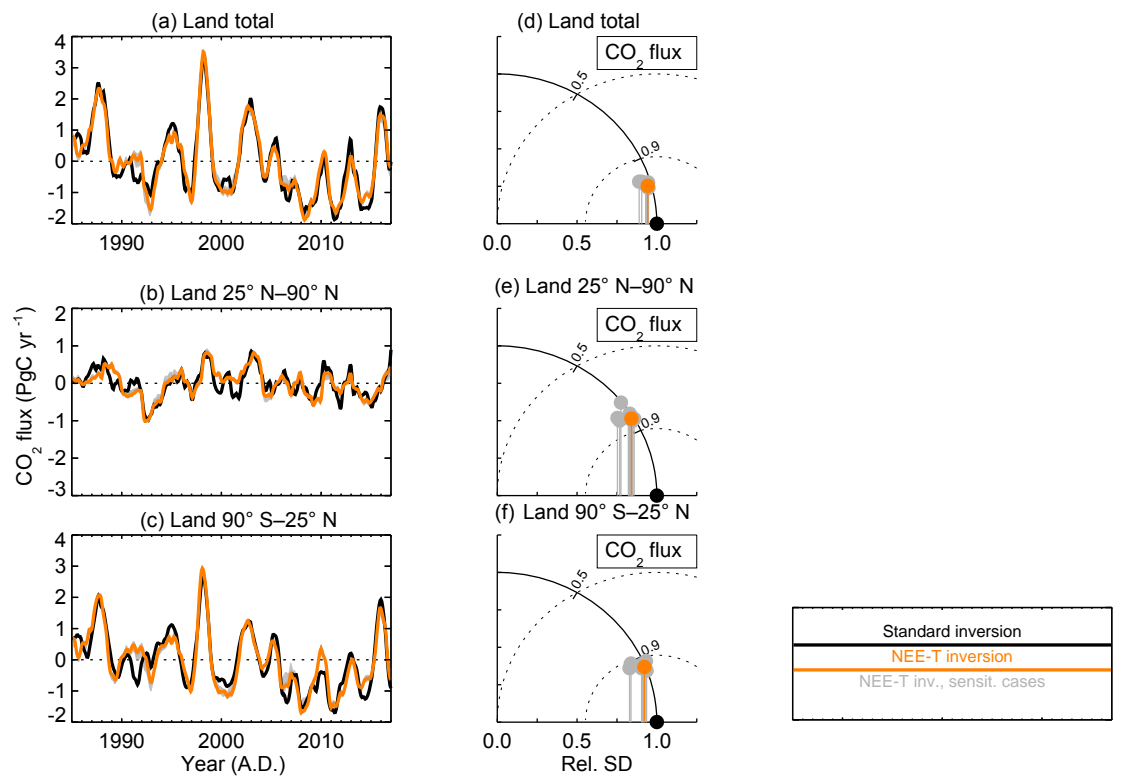

Figure 2. (a, b, c) Inter-annual anomalies of NEE integrated over all land (a), northern extratropical land (b), and tropical plus southern land (c) as estimated by the standard inversion (Sect. 2.1, black) and different runs of the NEE-T inversion (Sect. 2.2, orange). The grey band comprises the results of the sensitivity cases. $(\mathbf{d}, \mathbf{e}, \mathbf{f})$ Taylor diagrams quantifying the agreement between the NEE- $T$ inversions and the standard inversion. Due to the construction of the Taylor diagram (Taylor, 2001), the horizontal position of a point gives the relative fraction of the reference signal present in the test time series, while the vertical distance of this point from the horizontal axis gives the relative amplitude (temporal standard deviation) of any additional signal components uncorrelated with the reference signal.

and/or June in the northern extratropics (according to a correlation analysis of CRUNCEPv7 data, not shown), which would tend to amplify the direct temperature effect. In summer when photosynthesis is no longer limited by temperature, we find positive $\gamma$ NEE- $T$ values. Such positive $\gamma_{\text {NEE- } T}$ is consistent with enhanced respiration in warmer summers, but also with the fact that warmer-than-normal periods are often also drier, leading to reduced photosynthetic uptake or enhanced fire activity. In winter, NEE is not found to respond much to inter-annual climate variations. The interpretation of the seasonality of $\gamma_{\mathrm{NEE}-T}$ is confirmed by its latitude dependence: consistent with the later spring and shorter summer in the higher northern latitudes, the period of negative $\gamma_{\mathrm{NEE}-T}$ starts later there, and the period of positive $\gamma_{\mathrm{NEE}-T}$ is shorter.

In the tropics, we find stronger and less systematic variations in $\gamma_{\mathrm{NEE}-T}$. However, as indicated by the missing stippling, we also find larger disagreement between our sensitivity cases designed to embrace plausible ranges for the essential inputs and parameters in the algorithm (Sect. 2.3). This reveals that the seasonal variations in $\gamma_{\mathrm{NEE}-T}$ are of limited robustness here. Nevertheless, a clear feature in the tropics is the dominance of positive $\gamma \mathrm{NEE}-T$ values.

In southern extratropical America and Africa, the seasonal pattern has similarities with the northern extratropical pattern shifted by 6 months. The pattern in Australia is difficult to interpret, but also not very robust. Larger errors in the southern extratropics may conceivably arise because the much smaller land area involves a much smaller number of degrees of freedom available to satisfy the data constraints (remember that the oceanic flux cannot be adjusted in this inversion, while the $p \mathrm{CO}_{2}$-based ocean prior flux is actually less well constrained in the southern extratropics due to the much smaller density of $p \mathrm{CO}_{2}$ data).

\subsection{How much inter-annual variability of NEE can be reproduced by the seasonally resolved linear regression to $T$ ?}

The assumed linear relationship between NEE anomalies and air temperature anomalies around their respective seasonal cycles represents a strong abstraction of the complex underlying physiological and ecosystem processes. Nevertheless, the inter-annual variations of global total NEE estimated by the NEE- $T$ inversion are very similar to those estimated by the standard inversion (Fig. 2a). The agreement is confirmed by high correlation (Fig. 2d). For interpretation, we note that variations in the global total $\mathrm{CO}_{2}$ flux are very well constrained from atmospheric $\mathrm{CO}_{2}$ observations at timescales longer than the atmospheric mixing time (about 4 years) (Ballantyne et al., 2012). Variations on the year-to-year scale are already tightly constrained (Peylin et al., 2013). We thus use the global $\mathrm{CO}_{2}$ flux from the standard inversion with explicit inter-annual degrees of freedom as a benchmark. Since the ocean flux is identical in both the standard and NEE- $T$ 


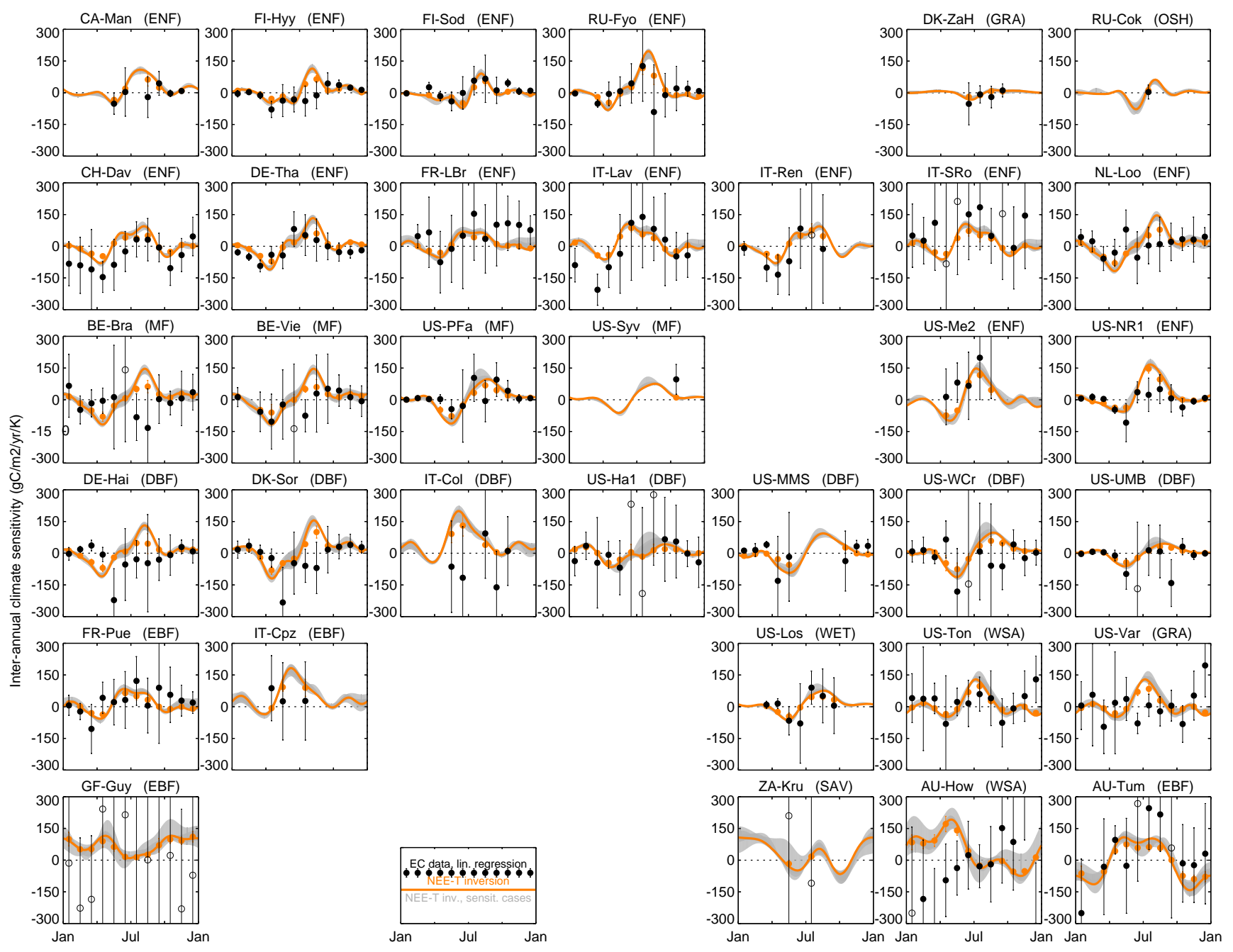

Figure 3. Comparison between the inter-annual climate sensitivities calculated from the inversion and from eddy covariance (EC) data for various sites with longer EC records. Black dots give the sensitivities $g_{\mathrm{NEE}-T}^{\mathrm{EC}}$ calculated by the linear regression of monthly $\mathrm{EC} \mathrm{CO}_{2}$ flux data (FLUXNET2015 data set) against monthly air temperature co-measured at the flux towers (months with data in only 6 years or less are discarded). The error bars around the dots comprise the confidence intervals of the regression slopes (at the $90 \%$ confidence level); if the confidence interval is above $300\left(\mathrm{gC} \mathrm{m}^{-2} \mathrm{yr}^{-1}\right) \mathrm{K}^{-1}$ (i.e. larger than the typical seasonal range), the corresponding dot is hollow. Orange and grey lines give the sensitivities $\gamma$ NEE- $T$ taken directly from various NEE- $T$ inversions (base and sensitivity cases as in Fig. 2) at the respective pixels enclosing the EC site locations. To allow for a more direct comparison between NEE- $T$ inversion results and EC data, sensitivities for the inversion (base case) have also been calculated by linear regression from the total monthly mean non-fossil $\mathrm{CO}_{2}$ flux and the temperature

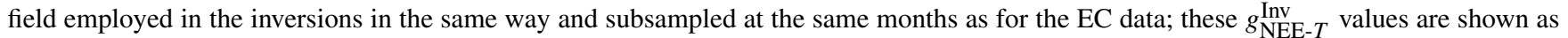
orange dots. Panels are roughly ordered by latitude and land cover type (DBF: deciduous broadleaf forest, EBF: evergreen broadleaf forest, ENF: evergreen needleleaf forest, GRA: grassland, MF: mixed forest, OSH: open shrubland, SAV: savanna, WET: permanent wetland, WSA: woody savanna). See Table 2 for EC site locations.

inversion runs, the high level of agreement in Fig. 2 (panels a and d) means that the spatially and seasonally resolved linear NEE- $T$ regression already provides a good approximation of global inter-annual NEE variations.

Almost the same level of agreement is also found for a split of the global NEE into a northern extratropical and a tropical plus southern extratropical contribution (Fig. 2b, c and e, f). Due to the faster atmospheric mixing within the extratropical hemispheres compared to the mixing across lati- tudes, these two NEE contributions are expected to be relatively well constrained by atmospheric data independently of each other. The linear approximation of the NEE- $T$ inversion is able to distinguish extratropical and tropical behaviour.

For a further split into smaller regions, in particular along longitude, inter-annual NEE variations from standard and NEE- $T$ inversions stay similar, but deviations get larger (not shown). This could indicate that the limits of the linear NEE$T$ relationship start to kick in at these scales. However, the 
NEE variations can no longer be expected to be well constrained from the atmospheric data at the regional scale. Thus, the discrepancy can also be caused by the standard inversion, while the NEE- $T$ inversion could be the more realistic one by profiting from the pixel-scale information added through the temperature field, as discussed in Sect. 4.1.

\subsection{Are the estimated patterns of $\gamma_{\mathrm{NEE}-T}$ compatible with ecosystem-scale eddy covariance data?}

Figure 3 compares inter-annual climate sensitivities (ordinate) calculated by the NEE- $T$ inversion with those calculated independently from eddy covariance (EC) data for each month of the year (abscissa). Each panel represents an EC site roughly arranged by ecosystem types and latitudes. The orange line with the surrounding grey band gives the sensitivities $\gamma$ NEE- $T$ from the various NEE- $T$ inversion runs as in Fig. 2 taken at the respective pixels enclosing the EC sites. The black dots are the sensitivities $g_{\mathrm{NEE}-T}^{\mathrm{EC}}$ calculated by the explicit linear regression of monthly EC flux records against the co-measured monthly air temperature (Sect. 2.4).

To allow for a fairer comparison between inversion results and EC data, additional colour dots give sensitivities $g_{\text {NEE- } T}^{\text {Inv }}$ calculated from the NEE- $T$ inversion results in the same way and subsampled at the same months as for the EC data (Sect. 2.4). At most EC sites, the sensitivities calculated by the inversion itself ( $\gamma \mathrm{NEE}-T$, orange lines) or by explicit regression afterwards ( $g_{\text {NEE- } T}^{\text {Inv }}$, orange dots) mostly agree within the confidence interval of the regression. This shows that the comparison of inversion and EC sensitivities is meaningful despite their differences in meaning and calculation (in particular, the trend influence (issue ii in Sect. 2.4) on $g_{\text {NEE- } T}^{\text {Inv }}$ turns out to be relatively small because the explicit regressions are only done over the limited time period spanned by the EC records).

Despite their completely independent sources of information and their remaining incompatibilities (Sect. 2.4), the sensitivities from the EC data and the atmospheric NEE- $T$ inversion have a similar order of magnitude and similar seasonal patterns for a majority of EC sites (Fig. 3). For most sites and months, the sensitivities agree within their confidence intervals. The level of agreement roughly depends on ecosystem type and latitude.

- Generally good consistency is found in high northern latitudes (line 1 of panels in Fig. 3) and at evergreen needleleaf forest (ENF) sites in temperate northern latitudes (line 2 and rightmost part of line 3 ).

- At mixed forest (MF) and deciduous broadleaf forest (DBF) sites in temperate northern latitudes (left part of line 3 and line 4), consistency is mostly good as well, though some months in spring or summer have more negative $g_{\text {NEE- } T}^{\text {Inv }}$ sensitivities from EC data (e.g. DEHai, DK-Sor, BE-Bra). However, the behaviour of DBF ecosystems is not an important contribution to larger- scale NEE variability because DBF ecosystems only cover 11 to $25 \%$ of the area around the sites shown.

- Generally good consistency within the confidence interval is also found at sites of various other ecosystem types in temperate northern latitudes (line 5).

- At the tropical and southern extratropical sites (last line), the comparison does not yield conclusive information, because the confidence intervals of the regression are much larger than the seasonal variations of both inversion and EC results. We can only state that the $g_{\text {NEE- } T}^{\text {Inv }}$ and $g_{\text {NEE- } T}^{\text {EC }}$ sensitivities do not contradict each other statistically. Some qualitative consistency is found at the Australian EBF site, even though the dominant vegetation round the site is shrubland (about $45 \%$ ).

Though this comparison partly remains inconclusive (as the confidence intervals at tropical and Southern Hemispheric sites are large, as $g_{\mathrm{NEE}-T}^{\mathrm{Inv}}$ and $g_{\mathrm{NEE}-T}^{\mathrm{EC}}$ are not actually fully comparable (Sect. 2.4), and as by far not all areas and dominating ecosystem types are represented), it does support the results of the NEE- $T$ inversion, at least in the northern extratropics.

\section{Discussion}

\subsection{NEE variations in the northern extratropics}

Given that we found robust seasonal patterns of $\gamma_{\text {NEE- }}$ which can be interpreted in terms of the fundamental physiological processes (Sect. 3.1), that these patterns are compatible with inferences from independent ecosystemscale eddy covariance (EC) measurements (Sect. 3.3), and that the corresponding inter-annual NEE variations are compatible with the atmospheric constraint on the most reliable large scales (Sect. 3.2), we conclude that the linear dependence of NEE anomalies on air temperature anomalies (as climate proxy) represents a meaningful approximative empirical description of the northern extratropical biosphere. The compatibility of the NEE- $T$ relationships inferred from large-scale atmospheric constraints and the ecosystem-scale EC constraints of dominating vegetation types suggests that the regional or continental NEE variations are to a substantial degree due to local variations linked to local climate anomalies; otherwise the NEE- $T$ inversion could not have worked. Given that, we expect the NEE- $T$ inversion to provide more realistic inter-annual NEE variations on regional scales than the standard inversion, which smoothly interpolates NEE on scales smaller than station-to-station differences (compare to the last paragraph of Sect. 3.2).

Note that as EC data measure fluxes on small spatial scales (a few hundreds of metres), the EC flux variations themselves cannot directly be compared to the inversion results representing NEE over (sub)continental scales and integrating over many ecosystem types and climate regimes. In con- 
trast to the fluxes, however, derived relationships (such as the NEE- $T$ relationships considered here) may well be able to bridge this scale gap.

Besides the inter-annual variations, the NEE- $T$ inversion also reproduces the small negative trend in NEE through its residual term $f_{\mathrm{NEE} \text {,Trend }}^{\text {adj }}$ in Eq. (2) (Fig. 2). Likewise, it reproduces the northern extratropical increase in seasonal cycle amplitude through its residual term $f_{\mathrm{NEE}, \mathrm{SCT} \text { rend }}^{\text {adj }}$ (not shown).

\subsection{NEE variations in the tropics}

In contrast to the northern extratropics, we did not find conclusive seasonal patterns of $\gamma_{\mathrm{NEE}-T}$ in the tropics (Sect. 3.1). However, despite the substantial uncertainty range of $\gamma_{\text {NEE-T }}$ (Fig. 1), the sensitivity cases reproduce almost identical inter-annual NEE variations in the tropics (see the narrow grey band around the NEE- $T$ estimate in Fig. 2c). This underlines the fact that pan-tropical NEE variations are actually well constrained from the atmospheric data, while the seasonal differences in $\gamma_{\mathrm{NEE}-T}$ arise to compensate for the set-up differences among the sensitivity cases. As shown below (Sect. 4.3), all the seasonally different $\gamma_{\mathrm{NEE}-T}$ estimates correspond to a similar effective sensitivity (having a positive value) on yearly timescales. Due to this, the NEE- $T$ inversion is found to possess predictive skill on the timescale of the El Niño-Southern Oscillation (Rödenbeck et al., 2018).

The positive effective $\gamma_{\text {NEE-T }}$ in the tropics (Sect. 3.1) is consistent with the strong positive correlation of atmospheric $\mathrm{CO}_{2}$ growth with large-scale tropical annual temperature (Wang et al., 2013). This is unlikely to arise from a direct temperature effect, however, because process studies (e.g. Meir et al., 2008; Bonal et al., 2008; Alden et al., 2016) point to water availability rather than temperature as the dominant control on the ecosystem scale. This is also confirmed by the large confidence intervals of the NEE- $T$ regression of the EC data from the only tropical site available here (GF-Guy, leftmost on last line of Fig. 3). A strong correlation with temperature can still arise statistically due to the strong link of temperature and precipitation anomalies over larger spatial scales (Berg et al., 2014). Moreover, the vapour pressure deficit (VPD) controlling photosynthesis responds particularly strongly to temperature variations in the warm tropical climate due to the non-linearity of the $\operatorname{VPD}(\mathrm{T})$ dependence (Monteith and Unsworth, 1990). Further, $T$ is spatially coherent over much larger areas in the tropics, while variability in water availability is local and averages out over larger spatial scales (Jung et al., 2017). Nevertheless, a direct temperature effect in the tropics was found by Clark et al. (2013), at least for a component flux of NEE (wood production) in 12-year plot data.

\subsection{An extended benchmark for process models}

Data-based empirical relationships between inter-annual NEE variations and air temperature variations have been proposed in the literature as benchmarks to evaluate biogeochemical process models. For example, Cox et al. (2013) calculated an effective global climate sensitivity of $5.1 \pm$ $0.9 \mathrm{PgC} \mathrm{yr}^{-1} \mathrm{~K}^{-1}$ over $1960-2010$ by regressing the annual $\mathrm{CO}_{2}$ growth rate observed at the station Mauna Loa (Hawaii) (taken as a proxy for the global total $\mathrm{CO}_{2}$ flux) against $30^{\circ} \mathrm{N}-30^{\circ} \mathrm{S}$ (both land and ocean) averaged air temperature (after detrending both time series by subtracting an 11-year running mean). In a similar way (using the average atmospheric growth rate from a varying set of background sites, a slightly different time series treatment, and $24^{\circ} \mathrm{N}-24^{\circ} \mathrm{S}$ land temperature), Wang et al. (2013) obtained a value of $3.5 \pm 0.6 \mathrm{PgC} \mathrm{yr}^{-1} \mathrm{~K}^{-1}$ over 1959-2011. Wang et al. (2014) regressed the mean Mauna Loa and South Pole $\mathrm{CO}_{2}$ growth rates against $23^{\circ} \mathrm{N}-23^{\circ} \mathrm{S}$ vegetated land temperature over moving 20-year windows and reported effective global climate sensitivities between $3.4 \pm 0.4 \mathrm{PgC} \mathrm{yr}^{-1} \mathrm{~K}^{-1}$ (during 1960-1979) and $5.4 \pm 0.4 \mathrm{PgC} \mathrm{yr}^{-1} \mathrm{~K}^{-1}$ (during 19922011).

The inversion results presented here allow us to extend these benchmarks in two ways. As a first extension, we can evaluate to what extent the inter-annual variations in local or averaged atmospheric $\mathrm{CO}_{2}$ growth rates are indeed equivalent to the inter-annual variations in the global total $\mathrm{CO}_{2}$ flux (as implicitly assumed in the above-mentioned studies) and to what extent the global total $\mathrm{CO}_{2}$ flux is indeed representative of global terrestrial NEE or, even more specifically, tropical NEE. This can be evaluated here because all these time series (spatially explicit $\mathrm{CO}_{2}$ fluxes with all their contributions, as well as the corresponding atmospheric $\mathrm{CO}_{2}$ variations at the measurement stations) are available within the inversion calculation. To ensure a mutually consistent treatment of these time series, we used running yearly averages (January through December, February through next January, etc.) of the flux time series and running yearly differences (next January minus January, next February minus February, etc., multiplied by $2.12 \mathrm{PgC} \mathrm{ppm}^{-1}$; Ballantyne et al., 2012) of the atmospheric $\mathrm{CO}_{2}$ time series. All these inter-annual time series were then regressed over 1985-2016 against annual tropical land temperature $\left(25^{\circ} \mathrm{N}-25^{\circ} \mathrm{S}\right)$ derived from the same temperature field without decadal variations as used in the NEE- $T$ inversion. The resulting effective climate sensitivities are shown in Fig. 4. The sensitivities of the total $\mathrm{CO}_{2}$ flux (solid bars in the middle) calculated from the standard inversion (black) or from the NEE- $T$ inversion (orange) are similar to each other and fall in between the values by Cox et al. (2013) and Wang et al. (2013). Part of the discrepancies between these results can be attributed to the different time periods and the different time series treatments (in particular, to the extent to which decadal variability has been removed). Figure 4, however, reveals another reason for the 
discrepancies: the sensitivity of the Mauna Loa growth rate (middle hashed blue bar) is larger than that of the global flux (solid bars). This cannot be due to a deficiency in the inversions to fit Mauna Loa's variability because the modelled Mauna Loa sensitivities (hashed bars next to the middle blue bar) agree well with the observed ones. Thus, a sensitivity calculated from the Mauna Loa growth rate (as in Cox et al., 2013) somewhat overestimates the sensitivity of the global flux. The Mauna Loa sensitivity is still much closer to that of the global $\mathrm{CO}_{2}$ flux than sensitivities calculated from most other stations: southern extratropical stations like the South Pole (or the mean of Mauna Loa and the South Pole as in Wang et al., 2014) lead to a substantial underestimation (it is unclear why the sensitivity reported by Wang et al. (2014) for the recent 1992-2011 period is nevertheless even higher than our Mauna Loa value), while northern extratropical stations like Point Barrow lead to an even stronger overestimation than Mauna Loa. This suggests that using a varying mixture of stations (as in Wang et al., 2013) can induce further errors, in particular when possible changes in sensitivity are considered. We note that the atmospheric inversions benefit from using multiple station records because the transport model links the atmospheric $\mathrm{CO}_{2}$ signals to their different areas of origin rather than the instantaneous link of the atmospheric signals to the global flux as in the direct use of station records.

Care is also needed in the interpretation of the estimated effective sensitivities: the sensitivity of the total $\mathrm{CO}_{2}$ flux (solid bars) underestimates that of global NEE only (horizontally hashed bars) because the ocean flux is substantially anti-correlated with NEE on the inter-annual timescale. The sensitivity of tropical-only NEE (vertically hashed bars) is smaller than that of global NEE, though the reduction is less than according to the ratio of land area, confirming the dominance of tropical NEE variations.

As a second extension of process model benchmarking, the data-based estimates of the spatially and seasonally resolved $\gamma_{\text {NEE- }} T$ from the NEE- $T$ inversion can directly be employed as target values by regressing the NEE simulated by the terrestrial biosphere or Earth system model against the model temperature for individual small regions and seasons across the years 1985-2016 and comparing these modelderived local and season-specific sensitivities to the databased values presented here (using the ensemble of sensitivity cases as a measure of uncertainty in $\gamma_{\mathrm{NEE}-T}$ ). Importantly, before regressing, the model NEE and temperature fields need to be deseasonalized, detrended, and filtered in the same way as done for the observed temperature in the NEE- $T$ inversion (Sect. 2.2) because the numerical $\gamma$ NEE- $T$ values are somewhat specific to the chosen filtering, in particular to the exact way to remove decadal variations (as is also the case for the effective global climate sensitivity targets by Cox et al., 2013, and Wang et al., 2013, 2014). For the northern extratropics, where $\gamma_{\text {NEE- }} T$ is quite robustly constrained and shows distinct spatial and seasonal patterns
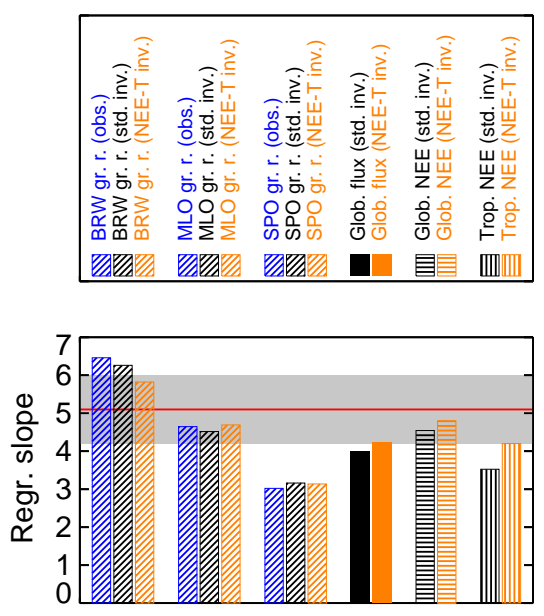

Figure 4. Effective large-scale inter-annual climate sensitivities $\left(\mathrm{PgC} \mathrm{yr}^{-1} \mathrm{~K}^{-1}\right.$ ) calculated from the standard inversion (black), from the NEE- $T$ inversion (orange), or from observed atmospheric $\mathrm{CO}_{2}$ (blue). The sensitivities refer to inter-annual variations in the $\mathrm{CO}_{2}$ growth rate at three selected atmospheric stations (Point Barrow, Alaska (BRW), Mauna Loa, Hawaii (MLO), and the South Pole (SPO), diagonally hashed), in the global total $\mathrm{CO}_{2}$ exchange (solid bars), in the global terrestrial NEE (horizontally hashed), or in tropical NEE $\left(25^{\circ} \mathrm{N}-90^{\circ} \mathrm{S}\right.$, vertically hashed $)$, all regressed against inter-annual variations in air temperature averaged across tropical land $\left(25^{\circ} \mathrm{N}-25^{\circ} \mathrm{S}\right)$ over $1985-2016$. The red line surrounded by grey shading denotes the result $5.1 \pm 0.9 \mathrm{PgC} \mathrm{yr}^{-1} \mathrm{~K}^{-1}$ by Cox et al. (2013), even though it is calculated in a slightly different way.

(Sect. 3.1), this offers a much more detailed benchmark of the process representation in the models than the existing singlevalued effective climate sensitivity of the global $\mathrm{CO}_{2}$ growth rate. For the tropics, unfortunately $\gamma_{\mathrm{NEE}-T}$ is not constrained well enough to do that, but due to the fact that pan-tropical NEE variations are nevertheless quite robust (Sect. 4.2), the effective climate sensitivity of tropical NEE from Fig. 4 (4.2 $\mathrm{PgC} \mathrm{yr}^{-1} \mathrm{~K}^{-1}$ with a range across the sensitivity cases of 3.8...4.4 $\mathrm{PgC} \mathrm{yr}^{-1} \mathrm{~K}^{-1}$ ) may be used as a specifically tropical target instead.

\subsection{Could the results be improved by using a multivariate regression against further climatic variables?}

We also tested the algorithm with precipitation $(P)$ or solar radiation as explanatory variables, individually or in multivariate combinations (not shown). While, for example, an NEE- $P$ inversion had almost as good an explanatory power as the NEE- $T$ inversion, a multivariate NEE- $T-P$ inversion did not explain much more NEE variations than the univariate NEE- $T$ inversion did already. This confirms the strong background correlations of air temperature with the other climate variables on inter-annual timescales. It also means that a multivariate regression would - despite a mathematically 
unique partitioning into contributions of the individual explanatory variables - likely not yield a uniquely interpretable attribution of NEE variability to different causes.

Given that, a univariate NEE- $T$ inversion seems advantageous because $T$ likely has data sets best constrained by observations. As a regression is confined to the variability present in the explanatory variables, using less well-observed or even modelled variables (as would be the case for precipitation or cloud cover) involves the risk of contamination.

\section{Conclusions and outlook}

The response of net ecosystem exchange (NEE) to climate anomalies has been estimated by linear regression against anomalies in air temperature $(T)$ within an atmospheric inversion based on a set of long-term atmospheric $\mathrm{CO}_{2}$ observations. The resulting spatially and seasonally resolved regression coefficients $\gamma \mathrm{NEE}-T$ are interpreted as an interannual climate sensitivity comprising the direct temperature response as well as responses to co-varying anomalies in other environmental conditions (e.g. moisture, radiation) (Sect. 4.4).

- The inferred inter-annual climate sensitivity $\gamma_{\text {NEE- } T}$ shows distinct and interpretable patterns along latitude and season. In particular, we find negative $\gamma_{\mathrm{NEE}-T}$ during spring and autumn (consistent with a temperature-limited photosynthesis) and positive $\gamma_{\text {NEE-T }}$ during summer (consistent with a water-limited photosynthesis) in all northern extratropical ecosystems (Sect. 3.1).

- Despite the complexity of the underlying plant and ecosystem processes, the spatially and seasonally resolved linear regression of NEE against temperature anomalies (taken as climate proxy) fitted to atmospheric $\mathrm{CO}_{2}$ data can reproduce a large fraction of inter-annual variations in the NEE, at least in the northern extratropics. This conclusion is based on the agreement of the inferred NEE variations with a time-explicit atmospheric inversion at well-constrained large spatial scales (Sect. 3.2) and the consistency of $\gamma_{\mathrm{NEE}-T}$ with independent calculations from eddy covariance data at small spatial scales (Sect. 3.3). Among the reasons for this potentially surprising finding is that the regression is only applied to the inter-annual anomalies of NEE around its mean seasonal cycle (rather than to the full range of seasonal temperature variations) and that the different behaviours in different seasons have been accounted for.
The results of the NEE- $T$ inversion can be applied to benchmark process models of the land biosphere or Earth system models: the spatially and seasonally resolved interannual climate sensitivity $\gamma$ NEE- $T$ can be calculated from the model output (using detrended NEE over the period 19852016 for consistency) and compared to the values presented here; this allows for a more detailed benchmark for the northern extratropical ecosystem processes than existing effective global sensitivities. Further, as its adjustable degrees of freedom are identically applied every year, the regression offers a way to bridge temporal gaps in the atmospheric $\mathrm{CO}_{2}$ records; it transfers information from the recent data-rich years into the more data-sparse past. Similarly, the NEE- $T$ regression allows us to forecast the $\mathrm{CO}_{2}$ flux for some years if forecasted air temperatures (and extrapolations of fossil fuel emissions and the ocean exchange) are available. As another application, the regression may help to uncover smaller decadal trends in the atmospheric $\mathrm{CO}_{2}$ signal by separating them from the larger inter-annual responses of NEE. By extending the calculation to the full period of atmospheric $\mathrm{CO}_{2}$ measurements (since the late 1950s; see Rödenbeck et al., 2018), we can investigate possible decadal changes in the inter-annual climate sensitivity $\gamma$ NEE- $T$.

Data availability. The inversion results are available for use in collaborative projects from the Jena CarboScope website at http:// www.BGC-Jena.mpg.de/CarboScope/ (http://dx.doi.org/10.17871/ CarboScope-s85oc_v4.1s, Rödenbeck and Heimann, 2017a; http:// dx.doi.org/10.17871/CarboScope-s04XocNEET_v4.1s, Rödenbeck and Heimann, 2017b). 


\section{Appendix A: More specification details of the inversion algorithm}

This Appendix first reviews the base set-up and implementation of the Jena CarboScope atmospheric $\mathrm{CO}_{2}$ inversion in its current version 4.1, from which the particular runs used in this study are derived (Sect. A1). Section A2 gives differences of the run s85oc_v4.1s used as standard inversion here. The further differences of the NEE- $T$ inversion s85ocNEET_v4.1s have already been described in Sect. 2.2.

For more details, formulas, or deeper explanations, the reader is referred to the technical report of Rödenbeck (2005).

\section{A1 The Jena CarboScope atmospheric $\mathrm{CO}_{2}$ inversion $\mathrm{v} 4.1$}

The Jena CarboScope $\mathrm{CO}_{2}$ inversion is a linear Bayesian atmospheric inversion estimating land-atmosphere and oceanatmosphere $\mathrm{CO}_{2}$ fluxes from long-term atmospheric $\mathrm{CO}_{2}$ mole fraction measurements (Rödenbeck, 2005). As the Jena CarboScope is particularly focused on inter-annual variations, flux estimates are only used over time periods homogeneously covered by all data records to avoid spurious jumps (or changes in the amplitude of variations) that can result from changes in the station set over time. To deal with the fact that many of today's measurement stations came into operation at various points in time during the last decades, the Jena CarboScope provides several runs, either over longer periods (the longest one currently being 1976-2016) with only a few stations or runs with more stations (currently up to 59) but correspondingly shorter periods. Despite these different "periods of validity", however, all base runs are carried out over 1955-2017, which includes time for spin-up and spin-down to minimize "edge effects". The Jena CarboScope inversion is regularly updated, mostly yearly to include the latest year of measurements. These updates may also involve some changes in the station sets according to data availability, as well as changes in the inversion set-up and implementation details. All results are available for use in collaborative projects from the Jena CarboScope website at http://www.BGC-Jena.mpg.de/CarboScope/.

The following provides some specification details for the current version 4.1 of the CarboScope inversion, also pointing out changes with respect to the previous version 3.8.

\section{A1.1 Grid resolution}

The $\mathrm{CO}_{2}$ fluxes have a daily time resolution and are represented on the grid of the transport model $\left(\approx 4^{\circ} \times 5^{\circ}\right.$, see below).

\section{A1.2 Prior information}

Bayesian prior information is used to regularize the otherwise underdetermined estimation. However, none of the ba- sic CarboScope inversion runs involve any information from terrestrial and oceanic carbon cycle models in order to transparently base the results on atmospheric information and thus to allow for an independent comparison to process models or to empirical models like the NEE- $T$ inversion.

The a priori probability distribution of the fluxes is not directly implemented through a covariance matrix, but indirectly through a statistical "flux model" that expresses the spatio-temporal $\mathrm{CO}_{2}$ flux field as a linear function of a vector of independent adjustable dimensionless parameters with zero mean and unit variance. This makes it easy to specify, e.g. timescale-dependent statistical properties, or to simultaneously specify temporal and spatial a priori correlations.

The prior flux of all land NEE components is zero. This means that the "error" in this prior is identical to the land $\mathrm{CO}_{2}$ flux itself; i.e. the a priori probability density describes the expected statistical properties of NEE. Its a priori uncertainties are proportional to the fraction of vegetated land area in each pixel taken as the sum of "crop", "dbf", "dnf", "ebf", "enf", "grass", and "shrub" fractions from SYNMAP (Jung et al., 2006). The results of the v4.1 inversions on larger spatial scales are still quite similar to v3.8 (which still used spatial patterns of a priori uncertainty derived from model output), confirming that the variability was not driven by these spatial patterns. The largest difference of v4.1 results to previous versions is a smaller amplitude of inter-annual variations in the tropical land fluxes.

NEE adjustments are split into the temporal mean, a large-scale mean seasonality, and (inter-annual) variations. The large-scale mean seasonality has a priori correlations of about $3825 \mathrm{~km}$ longitudinally, $1275 \mathrm{~km}$ latitudinally, and about 4 weeks in time. The correlation lengths of the other two flux contributions are about $1600 \mathrm{~km}$ longitudinally and about $800 \mathrm{~km}$ latitudinally and in the "variations" part 2 weeks in time. For practical reasons, the temporal variations in all adjustable terms are implemented as Fourier series. The temporal correlations can then simply be implemented by downweighting the a priori uncertainties of the Fourier modes with higher frequencies according to the spectrum corresponding to the desired autocorrelation function. The split into long-term, seasonal, and non-seasonal contributions can be implemented by simply activating only the corresponding part of the Fourier series. Note that not only the "mean seasonality" part but also the "variations" part contains seasonal Fourier terms to allow seasonal variability to also be adjusted on the smaller spatial scales.

Ocean fluxes are implemented analogously to land NEE, with a priori uncertainties proportional to the ocean fraction and slightly longer a priori spatial correlations (about $1912 \mathrm{~km}$ longitudinally and about $956 \mathrm{~km}$ latitudinally). In contrast to land NEE, however, the mean spatial flux pattern and its mean seasonal cycle are not adjusted, but prescribed to the mean seasonal cycle of the flux estimates oc_v1.4 (update of Rödenbeck et al., 2014) based on an interpolation of $p \mathrm{CO}_{2}$ data from the SOCATv4 database (Bakker et al., 
2016). Only the (inter-annual) ocean flux variability can be adjusted by the inversion in the basic 44.1 runs (see the difference in the present "standard inversion" in Sect. A2 below).

The fossil fuel emission prior is taken from monthly values of CDIAC (Andres et al., 2016). The years after 2013 have been extrapolated by global scaling factors based on the ratios in the emission totals from Le Quéré et al. (2016, update for year 2016). There are no inverse adjustments to fossil fuel emissions.

\section{A1.3 Data treatment}

The CarboScope inversion uses the individual data points in the atmospheric $\mathrm{CO}_{2}$ records (flask pair values or hourly averages). In order to prevent the in situ records with hourly data from dominating the result, a "data density weighting" has been implemented. It artificially increases the modeldata mismatch uncertainty of data points from dense records in such a way that weekly periods of data always have the same impact on the results.

The individual $\mathrm{CO}_{2}$ data points are screened for outliers by a " $2 \sigma$ criterion" (newly introduced in CarboScope version v4.1): a pre-run of the inversion is done using the base CarboScope set-up and a large set of stations potentially used in later runs. Then, the $\mathrm{CO}_{2}$ mole fraction residuals between a forward run from the posterior fluxes and the data are considered. For each station, data points are removed if their residual is larger than 2 standard deviations across all residuals of that station. This procedure is similar to the outlier flagging done routinely by many atmospheric data providers. By doing it within the inversion, the deficiencies of the transport model in reproducing small-scale circulation are taken into account to some extent. The procedure can also be understood as an approximate way to implement a non-Gaussian probability density for the model-data mismatch: as residuals larger than $2 \sigma$ are very unlikely in the Gaussian distribution, an inversion assuming Gaussian model-data mismatches will respond strongly to "outliers" to reduce these mismatches; in contrast, the " $2 \sigma$ screening" effectively assigns an infinitely large uncertainty to these data points. The results mostly stay similar after this screening, but some flux anomalies get removed. In most cases, these anomalies were unrobust in that they were dampened much faster than other anomalies when increasing the strength of the prior constraint (parameter $\mu$ in Rödenbeck, 2005). For example, many of the spikes in the $\mathrm{CO}_{2}$ record of station KEY and their effect on the $\mathrm{CO}_{2}$ flux estimates for northern temperate America are removed by the screening. We interpret these spikes as the influence of local fossil fuel emissions, which would be mistaken by the inversion as regional signals. This interpretation is supported by the fact that more and more of these spikes occur in the more recent decades. The introduction of the $2 \sigma$ screening made it possible to re-add further stations with pronounced spikes, such as station TAP.

\section{A1.4 Further implementation details}

Atmospheric tracer transport in the global CarboScope inversions is simulated by the TM3 model (Heimann and Körner, 2003) (resolution $\approx 4^{\circ} \times 5^{\circ} \times 19$ layers) driven by meteorological fields from the NCEP reanalysis (Kalnay et al., 1996). Since CarboScope v4.1, NCEP has been used again (rather than ERA-Interim) as only NCEP is currently available before 1980 .

The cost function minimization uses the conjugate gradient algorithm enhanced by a re-orthonormalization after each iteration to avoid the usual degradation of the convergence rate. The re-orthonormalization requires storing the state vectors and gradients of all iterations performed, which opens the additional possibility of also recalculating the solution for tighter prior constraints without the need to run the iterative minimization again. It also accumulates information about the a posteriori covariance matrix, though the actual calculation of matrix elements generally needs further dedicated iterations.

\section{A2 The standard inversion s85oc_v4.1s}

In comparison to the basic $\mathrm{v} 4.1$ runs (Sect. A1), the particular run s85oc_v4.1s involves three specifics or differences.

The station set $\mathrm{s} 85 \mathrm{v} 21$ is used, comprising the 23 stations marked with * in Table 1.

The calculation is done over the shorter period 1980-2017 (indicated by the appended "s" in the version tag).

The entire ocean flux (including inter-annual variations) is fixed to the CarboScope estimates oc_v1.5 (update of Rödenbeck et al., 2014) based on an interpolation of $p \mathrm{CO}_{2}$ data from the SOCATv5 database (Bakker et al., 2016). Fixed ocean fluxes are used here because atmospheric inversions are known to have limited capability to correctly assign signals to land or ocean (Peylin et al., 2013). While this error is relatively small for the land fluxes, it means a large relative error for the ocean fluxes because the ocean variability is much smaller than the land variability. The $p \mathrm{CO}_{2}$ data offer a much closer constraint on ocean $\mathrm{CO}_{2}$ fluxes in well-observed regions (northern extratropics, tropical Pacific) and constrain at least some features (seasonality, decadal trends) in most ocean areas. (For the NEE- $T$ inversion, fixed ocean fluxes are particularly beneficial because they avoid the need for time-dependent degrees of freedom.) 
Competing interests. The authors declare that they have no conflict of interest.

Special issue statement. This article is part of the special issue "The 10th International Carbon Dioxide Conference (ICDC10) and the 19th WMO/IAEA Meeting on Carbon Dioxide, other Greenhouse Gases and Related Measurement Techniques (GGMT-2017) (AMT/ACP/BG/CP/ESD inter-journal SI)". It is a result of the 10th International Carbon Dioxide Conference, Interlaken, Switzerland, 21-25 August 2017.

Acknowledgements. This study would not be possible without the sustained work of many colleagues involved in the measurement and distribution of atmospheric $\mathrm{CO}_{2}$ data; we would like to thank them all for their support. We are grateful to Luiz Aragão, Pierre Gentine, Martin Jung, Eric Kort, and Markus Reichstein for inspiring discussions. We would like to thank the staff of the DKRZ supercomputing centre for their great support, in particular Hendryk Bockelmann for optimizing the inversion and TM3 codes. We gratefully acknowledge that this work uses eddy covariance data acquired and shared by the FLUXNET community, including these networks: AmeriFlux, AfriFlux, AsiaFlux, CarboAfrica, CarboEuropeIP, CarboItaly, CarboMont, ChinaFlux, FluxnetCanada, GreenGrass, ICOS, KoFlux, LBA, NECC, OzFlux-TERN, TCOS-Siberia, and USCCC. The FLUXNET eddy covariance data processing and harmonization was carried out by the European Fluxes Database Cluster, the AmeriFlux Management Project, and the Fluxdata project of FLUXNET with the support of the CDIAC and ICOS Ecosystem Thematic Center and the OzFlux, ChinaFlux, and AsiaFlux offices. This project was supported in part by the US NSF and the National Aeronautics and Space Administration (NASA) under grants 1304270 and NNX17AE74G.

The article processing charges for this open-access publication were covered by the Max Planck Society.

Edited by: Christoph Heinze

Reviewed by: two anonymous referees

\section{References}

Alden, C. B., Miller, J. B., Gatti, L. V., Gloor, M. M., Guan, K., Michalak, A. M., van der Laan-Luijkx, I. T., Touma, D., Andrews, A., Basso, L. S., Correia, C. S. C., Domingues, L. G., Joiner, J., Krol, M. C., Lyapustin, A. I., Peters, W., Shiga, Y. P., Thoning, K., van der Velde, I. R., van Leeuwen, T. T., Yadav, V., and Diffenbaugh, N. S.: Regional atmospheric $\mathrm{CO}_{2}$ inversion reveals seasonal and geographic differences in Amazon net biome exchange, Glob. Change Biol., 22, 3427-3443, https://doi.org/10.1111/gcb.13305, 2016.

Andres, R., Boden, T., and Marland, G.: Monthly Fossil-Fuel $\mathrm{CO}_{2}$ Emissions: Mass of Emissions Gridded by One Degree Latitude by One Degree Longitude, Carbon Dioxide Information Analysis Center, Oak Ridge National Laboratory, U.S. Department of Energy, Oak Ridge, Tenn., USA, https://doi.org/10.3334/CDIAC/ffe.MonthlyMass.2016, 2016.
Baker, D. F., Law, R. M., Gurney, K. R., Rayner, P., Peylin, P., Denning, A. S., Bousquet, P., Bruhwiler, L., Chen, Y.-H., Ciais, P., Fung, I. Y., Heimann, M., John, J., Maki, T., Maksyutov, S., Masarie, K., Prather, M., Pak, B., Taguchi, S., and Zhu, Z.: TransCom 3 inversion intercomparison: Impact of transport model errors on the interannual variability of regional $\mathrm{CO}_{2}$ fluxes, 1988-2003, Glob. Biogeochem. Cy., 20, GB1002, https://doi.org/10.1029/2004GB002439, 2006.

Bakker, D. C. E., Pfeil, B., Landa, C. S., Metzl, N., O'Brien, K. M., Olsen, A., Smith, K., Cosca, C., Harasawa, S., Jones, S. D., Nakaoka, S.-I., Nojiri, Y., Schuster, U., Steinhoff, T., Sweeney, C., Takahashi, T., Tilbrook, B., Wada, C., Wanninkhof, R., Alin, S. R., Balestrini, C. F., Barbero, L., Bates, N. R., Bianchi, A. A., Bonou, F., Boutin, J., Bozec, Y., Burger, E. F., Cai, W.-J., Castle, R. D., Chen, L., Chierici, M., Currie, K., Evans, W., Featherstone, C., Feely, R. A., Fransson, A., Goyet, C., Greenwood, N., Gregor, L., Hankin, S., Hardman-Mountford, N. J., Harlay, J., Hauck, J., Hoppema, M., Humphreys, M. P., Hunt, C. W., Huss, B., Ibánhez, J. S. P., Johannessen, T., Keeling, R., Kitidis, V., Körtzinger, A., Kozyr, A., Krasakopoulou, E., Kuwata, A., Landschützer, P., Lauvset, S. K., Lefèvre, N., Lo Monaco, C., Manke, A., Mathis, J. T., Merlivat, L., Millero, F. J., Monteiro, P. M. S., Munro, D. R., Murata, A., Newberger, T., Omar, A. M., Ono, T., Paterson, K., Pearce, D., Pierrot, D., Robbins, L. L., Saito, S., Salisbury, J., Schlitzer, R., Schneider, B., Schweitzer, R., Sieger, R., Skjelvan, I., Sullivan, K. F., Sutherland, S. C., Sutton, A. J., Tadokoro, K., Telszewski, M., Tuma, M., van Heuven, S. M. A. C., Vandemark, D., Ward, B., Watson, A. J., and Xu, S.: A multidecade record of high-quality $f \mathrm{CO}_{2}$ data in version 3 of the Surface Ocean CO2 Atlas (SOCAT), Earth Syst. Sci. Data, 8, 383413, https://doi.org/10.5194/essd-8-383-2016, 2016.

Baldocchi, D. D.: Assessing the eddy covariance technique for evaluating carbon dioxide exchange rates of ecosystems: past, present and future, Glob. Change Biol., 9, 479-492, https://doi.org/10.1046/j.1365-2486.2003.00629.x, 2003.

Baldocchi, D., Falge, E., Gu, L. H., Olson, R., Hollinger, D., Running, S., Anthoni, P., Bernhofer, C., Davis, K., Evans, R., Fuentes, J., Goldstein, A., Katul, G., Law, B., Lee, X. H., Malhi, Y., Meyers, T., Munger, W., Oechel, W., U, K. T. P., Pilegaard, K., Schmid, H. P., Valentini, R., Verma, S., Vesala, T., Wilson, K., and Wofsy, S.: FLUXNET: A new tool to study the temporal and spatial variability of ecosystem-scale carbon dioxide, water vapor, and energy flux densities, B. Am. Meteorol. Soc., 82, 2415-2434, 2001.

Ballantyne, A., Alden, C. B., Miller, J., Tans, P., and White, J. W. C.: Increase in observed net carbon dioxide uptake by land and oceans during the past 50 years, Nature, 488, 70-73, 2012.

Berg, A., Lintner, B. R., Findell, K., Seneviratne, S. I., van den Hurk, B., Ducharne, A., Chéruy, F., Hagemann, S., Lawrence, D. M., Malyshev, S., Meier, A., and Gentine, P.: Interannual Coupling between Summertime Surface Temperature and Precipitation over Land: Processes and Implications for Climate Change, J. Climate, 28, 1308-1328, https://doi.org/10.1175/JCLI-D-1400324.1, 2014.

Bonal, D., Bosc, A., Ponton, S., Goret, J.-Y., Burban, B., Gross, P., Bonnefond, J.-M., Elbers, J., Longdoz, B., Epron, D., Guehl, J.-M., and Granier, A.: Impact of severe dry season on net ecosystem exchange in the Neotropical rainfor- 
est of French Guiana, Glob. Change Biol., 14, 1917-1933, https://doi.org/10.1111/j.1365-2486.2008.01610.x, 2008.

Buitenhuis, E., Rivkin, R., Sailley, S., and Le Quéré, C.: Biogeochemical fluxes through microzooplankton, Global Biogeochem. Cy., 24, GB4015, https://doi.org/10.1029/2009GB003601, 2010.

Clark, D. A., Clark, D. B., and Oberbauer, S. F.: Field-quantified responses of tropical rainforest aboveground productivity to increasing $\mathrm{CO}_{2}$ and climatic stress, 1997-2009, J. Geophys. Res.-Biogeo., 118, 783-794, https://doi.org/10.1002/jgrg.20067, 2013.

Colombo, T. and Santaguida, R.: Atmospheric $\mathrm{CO}_{2}$ record from in situ measurements at Mt. Cimone, in: Trends '93: A compendium of Data on Global Change, edited by: Boden, T. A., Kaiser, D. P., Sepanski, R. J., and Stoss, F. W., ORNL/CDIAC65. Carbon Dioxide Information Analysis Center, Oak Ridge National Laboratory, Oak Ridge, Tenn., USA, 1994.

Conway, T., Tans, P., Waterman, L., Thoning, K., Kitzis, D., Masarie, K., and Zhang, N.: Evidence for interannual variability of the carbon cycle from the national oceanic and atmospheric administration climate monitoring and diagnostics laboratory global air sampling network, J. Geophys. Res., 99, 2283122855, 1994.

Cox, P. M., Pearson, D., Booth, B. B., Friedlingstein, P., Huntingford, C., Jones, C. D., and Luke, C. M.: Sensitivity of tropical carbon to climate change constrained by carbon dioxide variability, Nature, 494, 341-344, https://doi.org/10.1038/nature11882, 2013.

Dee, D. P., Uppala, S. M., Simmons, A. J., Berrisford, P., Poli, P., Kobayashi, S., Andrae, U., Balmaseda, M. A., Balsamo, G., Bauer, P., Bechtold, P., Beljaars, A. C. M., van de Berg, L., Bidlot, J., Bormann, N., Delsol, C., Dragani, R., Fuentes, M., Geer, A. J., Haimberger, L., Healy, S. B., Hersbach, H., Hólm, E. V., Isaksen, L., llberg, P. K., Köhler, M., Matricardi, M., McNally, A. P., Monge-Sanz, B. M., Morcrette, J.-J., Park, B.-K., Peubey, C., de Rosnay, P., Tavolato, C., Thépaut, J.-N., and Vitart, F.: The era-interim reanalysis: Configuration and performance of the data assimilation system, Q. J. Roy. Meteor. Soc., 137, 553-597, 2011.

Francey, R., Steele, L., Spencer, D., Langenfelds, R., Law, R., Krummel, P., Fraser, P., Etheridge, D., Derek, N., Coram, S., Cooper, L., Allison, C., Porter, L., and Baly, S.: The CSIRO (Australia) measurement of greenhouse gases in the global atmosphere, Report of the 11th WMO/IAEA Meeting of Experts on Carbon Dioxide Concentration and Related Tracer Measurement Techniques, Tokyo, Japan, September 2001, edited by: Toru, S. and Kazuto, S., World Meteorological Organization Global Atmosphere Watch, 97-111, 2003.

Friedlingstein, P., Bopp, L., Ciais, P., Dufresne, J.-L., Fairhead, L., Le Treut, H., Monfray, P., and Orr, J.: Positive feedback between future climate change and the carbon cycle, Geophys. Res. Lett., 28, 1543-1546, 2001.

Friedlingstein, P., Andrew, R. M., Rogelj, J., Peters, G. P., Canadell, J. G., Knutti, R., Luderer, G., Raupach, M. R., Schaeffer, M., van Vuuren, D. P., and Le Quéré, C.: Persistent growth of $\mathrm{CO}_{2}$ emissions and implications for reaching climate targets, Nat. Geosci., 7, 709-715, https://doi.org/10.1038/NGEO2248, 2014.

GISTEMP Team: GISS Surface Temperature Analysis (GISTEMP), NASA Goddard Institute for Space Studies, available at: https: //data.giss.nasa.gov/gistemp/ (last access: 13 June 2017), 2017.
Gomez-Pelaez, A. and Ramos, R.: Improvements in the Carbon Dioxide and Methane Continuous Measurement Programs at Izaña Global GAW Station (Spain) during 2007-2009, GAW report (No. 194), 133-138, 15th WMO/IAEA Meeting of Experts on Carbon Dioxide, Other Greenhouse Gases, and Related Tracer Measurement Techniques (Jena, Germany; September $7-$ 10, 2009), edited by: Brand, W. A., World Meteorological Organization, 2011

Graven, H. D., Keeling, R. F., Piper, S. C., Patra, P. K., Stephens, B. B., Wofsy, S. C., Welp, L. R., Sweeney, C., Tans, P. P., Kelley, J. J., Daube, B. C., Kort, E. A., Santoni, G. W., and Bent, J. D.: Enhanced Seasonal Exchange of $\mathrm{CO}_{2}$ by Northern Ecosystems Since 1960, Science, 341, 1085-1089, https://doi.org/10.1126/science.1239207, 2013.

Hansen, J., Ruedy, R., Sato, M., and Lo, K.: Global surface temperature change, Rev. Geophys., 48, RG4004, https://doi.org/10.1029/2010RG000345, 2010.

Haszpra, L., Barcza, Z., Bakwin, P. S., Berger, B. W., Davis, K. J., and Weidinger, T.: Measuring system for the long-term monitoring of biosphere/atmosphere exchange of carbon dioxide, J. Geophys. Res., 106, 3057-3070, 2001.

Heimann, M. and Körner, S.: The global atmospheric tracer model TM3, Tech. Rep. 5, Max Planck Institute for Biogeochemistry, Jena, Germany, 2003.

Jung, M., Henkel, K., Herold, M., and Churkina, G.: Exploiting synergies of global land cover products for carbon cycle modeling, Remote Sens. Environ., 101, 534-553, 2006.

Jung, M., Reichstein, M., Schwalm, C. R., Huntingford, C., Sitch, S., Ahlström, A., Arneth, A., Camps-Valls, G., Ciais, P., Friedlingstein, P., Gans, F., Ichii, K., Jain, A. K., Kato, E., Papale, D., Poulter, B., Raduly, B., Rödenbeck, C., Tramontana, G., Viovy, N., Wang, Y.-P., Weber, U., Zaehle, S., and Zeng, N.: Compensatory water effects link yearly global land $\mathrm{CO}_{2}$ sink changes to temperature, Nature, 541, 516-520, https://doi.org/10.1038/nature20780, 2017.

Kalnay, E., Kanamitsu, M., Kistler, R., Collins, W., Deaven, D., Gandin, L., Iredell, M., Saha, S., White, G., Woollen, J., Zhu, Y., Chelliah, M., Ebisuzaki, W., Higgins, W., Janowiak, J., Mo, K. C., Ropelewski, C., Wang, J., Leetmaa, A., Reynolds, R., Jenne, R., and Joseph, D.: The NCEP/NCAR 40-year reanalysis project, B. Am. Meteorol. Soc., 77, 437-471, 1996.

Keeling, C. D., Piper, S. C., Bacastow, R. B., Wahlen, M., Whorf, T. P., Heimann, M., and Meijer, H. A.: Atmospheric $\mathrm{CO}_{2}$ and ${ }^{13} \mathrm{CO}_{2}$ exchange with the terrestrial biosphere and oceans from 1978 to 2000: observations and carbon cycle implications, 83113, in: A History of Atmospheric $\mathrm{CO}_{2}$ and its effects on Plants, Animals, and Ecosystems, edited by: Ehleringer, J. R., Cerling, T. E., and Dearing, M. D., Springer Verlag, New York, 2005.

Kilkki, J., Aalto, T., Hatakka, J., Portin, H., and Laurila, T.: Atmospheric $\mathrm{CO}_{2}$ observations at Finnish urban and rural sites, Boreal Environ. Res., 20, 227-242, 2015.

Labuschagne, C., Brunke, E.-G., and Scheel, H.: Global Trace Gas Trends as Observed at the Cape Point Global Atmosphere Watch (GAW) Station, presented at: Global Change and Regional Sustainability in South Africa, Kirstenbosch, Cape Town, 2003.

Le Quéré, C., Andrew, R. M., Canadell, J. G., Sitch, S., Korsbakken, J. I., Peters, G. P., Manning, A. C., Boden, T. A., Tans, P. P., Houghton, R. A., Keeling, R. F., Alin, S., Andrews, O. D., Anthoni, P., Barbero, L., Bopp, L., Chevallier, F., Chini, L. P., 
Ciais, P., Currie, K., Delire, C., Doney, S. C., Friedlingstein, P., Gkritzalis, T., Harris, I., Hauck, J., Haverd, V., Hoppema, M., Klein Goldewijk, K., Jain, A. K., Kato, E., Körtzinger, A., Landschützer, P., Lefèvre, N., Lenton, A., Lienert, S., Lombardozzi, D., Melton, J. R., Metzl, N., Millero, F., Monteiro, P. M. S., Munro, D. R., Nabel, J. E. M. S., Nakaoka, S.-I., O’Brien, K., Olsen, A., Omar, A. M., Ono, T., Pierrot, D., Poulter, B., Rödenbeck, C., Salisbury, J., Schuster, U., Schwinger, J., Séférian, R., Skjelvan, I., Stocker, B. D., Sutton, A. J., Takahashi, T., Tian, H., Tilbrook, B., van der Laan-Luijkx, I. T., van der Werf, G. R., Viovy, N., Walker, A. P., Wiltshire, A. J., and Zaehle, S.: Global Carbon Budget 2016, Earth Syst. Sci. Data, 8, 605-649, https://doi.org/10.5194/essd-8-605-2016, 2016.

Levin, I., Graul, R., and Trivett, N.: Long term observations of atmospheric $\mathrm{CO}_{2}$ and carbon isotopes at continental sites in Germany, Tellus B, 47, 23-34, https://doi.org/10.1034/j.16000889.47.issue1.4.x, 1995 .

Manning, A. C. and Keeling, R. F.: Global oceanic and land biotic carbon sinks from the Scripps atmospheric oxygen flask sampling network, Tellus B, 58, 95-116, https://doi.org/10.1111/j.1600-0889.2006.00175.x, 2006.

Meir, P., Metcalfe, D. B., Costa, A. C. L., and Fisher, R. A.: The fate of assimilated carbon during drought: impacts on respiration in Amazon rainforests, Philos. T. Roy. Soc. B, 363, 1849-1855, https://doi.org/10.1098/rstb.2007.0021, 2008.

Monfray, P., Ramonet, M., and Beardsmore, D.: Longitudinal and vertical $\mathrm{CO}_{2}$ gradients over the subtropical/subantarctic oceanic sink, Tellus B, 48, 445-446, https://doi.org/10.3402/tellusb.v48i4.15925, 1996.

Monteith, J. L. and Unsworth, M. H.: Principles of Environmental Physics, Butterworth-Heinemann, 1990.

Morimoto, S., Nakazawa, T., Aoki, S., Hashida, G., and Yamanouchi, T.: Concentration variations of atmospheric $\mathrm{CO}_{2}$ observed at Syowa Station, Antarctica from 1984 to 2000, Tellus B, 55, 170-177, https://doi.org/10.1034/j.1600-0889.2003.01471.x, 2003.

Myeni, R., Keeling, C., Tucker, C., Asrar, G., and Nemani, R.: Increased plant growth in the northern high latitudes from 1981 to 1991, Nature, 386, 698-702, 1997.

Mystakidis, S., Seneviratne, S. I., Gruber, N., and Davin, E. L.: Hydrological and biogeochemical constraints on terrestrial carbon cycle feedbacks, Environ. Res. Lett., 12, 014009, https://doi.org/10.1088/1748-9326/12/1/014009, 2017.

Newsam, G. N. and Enting, I. G.: Inverse problems in atmospheric constituent studies: I. Determination of surface sources under a diffusive transport approximation, Inverse Probl., 4, 1037-1054, 1988.

Peylin, P., Law, R. M., Gurney, K. R., Chevallier, F., Jacobson, A. R., Maki, T., Niwa, Y., Patra, P. K., Peters, W., Rayner, P. J., Rödenbeck, C., van der Laan-Luijkx, I. T., and Zhang, X.: Global atmospheric carbon budget: results from an ensemble of atmospheric $\mathrm{CO}_{2}$ inversions, Biogeosciences, 10, 6699-6720, https://doi.org/10.5194/bg-10-6699-2013, 2013.

Piao, S., Liu, Z., Wang, T., Peng, S., Ciais, P., Huang, M., Ahlstrom, A., Burkhart, J. F., Chevallier, F., Janssens, I. A., Jeong, S.J., Lin, X., Mao, J., Miller, J., Mohammat, A., Myneni, R. B., nuelas, J. P., Shi, X., Stohl, A., Yao, Y., Zhu, Z., and Tans, P. P.: Weakening temperature control on the interannual variations of spring carbon uptake across northern lands, Nature Cli- mate Change, 7, 359-363, https://doi.org/10.1038/nclimate3277, 2017.

Rafelski, L. E., Piper, S. C., and Keeling, R. F.: Climate effects on atmospheric carbon dioxide over the last century, Tellus B, 61, 718-731, 2009.

Rayner, P., Enting, I., Francey, R., and Langenfelds, R.: Reconstructing the recent carbon cycle from atmospheric $\mathrm{CO}_{2}, \delta^{13} \mathrm{CO}_{2}$ and $\mathrm{O}_{2} / \mathrm{N}_{2}$ observations, Tellus $\mathrm{B}, 51,213-232,1999$.

Rödenbeck, C.: Estimating $\mathrm{CO}_{2}$ sources and sinks from atmospheric mixing ratio measurements using a global inversion of atmospheric transport, Tech. Rep. 6, Max Planck Institute for Biogeochemistry, Jena, Germany, 2005.

Rödenbeck, C. and Heimann, M.: Jena CarboScope: Atmospheric $\mathrm{CO}_{2}$ inversion, http://dx.doi.org/10.17871/CarboScope-s85oc_ v4.1s, 2017a.

Rödenbeck, C. and Heimann, M.: Jena CarboScope: Atmospheric $\mathrm{CO}_{2}$ inversion, http://dx.doi.org/10.17871/ CarboScope-s04XocNEET_v4.1s, 2017b.

Rödenbeck, C., Houweling, S., Gloor, M., and Heimann, M.: $\mathrm{CO}_{2}$ flux history 1982-2001 inferred from atmospheric data using a global inversion of atmospheric transport, Atmos. Chem. Phys., 3, 1919-1964, https://doi.org/10.5194/acp-3-1919-2003, 2003.

Rödenbeck, C., Bakker, D. C. E., Metzl, N., Olsen, A., Sabine, C., Cassar, N., Reum, F., Keeling, R. F., and Heimann, M. Interannual sea-air $\mathrm{CO}_{2}$ flux variability from an observationdriven ocean mixed-layer scheme, Biogeosciences, 11, 45994613, https://doi.org/10.5194/bg-11-4599-2014, 2014.

Rödenbeck, C., Zaehle, S., Keeling, R., and Heimann, M.: History of El Nino impacts on the global carbon cycle 1957-2016: A quantification from atmospheric $\mathrm{CO}_{2}$ data, Philos. T. Roy. Soc. B., under review, 2018.

Taylor, K. E.: Summarizing multiple aspects of model performance in a single diagram, J. Geophys. Res., 106, 7183-7192, 2001.

Thompson, R. L., Manning, A. C., Gloor, E., Schultz, U., Seifert, T., Hänsel, F., Jordan, A., and Heimann, M.: In-situ measurements of oxygen, carbon monoxide and greenhouse gases from Ochsenkopf tall tower in Germany, Atmos. Meas. Tech., 2, 573591, https://doi.org/10.5194/amt-2-573-2009, 2009.

Tohjima, Y., Mukai, H., Nojiri, Y., Yamagishi, H., and Machida, T.: Atmospheric $\mathrm{O}_{2} / \mathrm{N}_{2}$ measurements at two Japanese sites: estimation of global oceanic and land biotic carbon sinks and analysis of the variations in atmospheric potential oxygen (APO), Tellus B, 60, 213-225, 2008.

Wang, W., Ciais, P., Nemani, R. R., Canadell, J. G., Piao, S., Sitch, S., White, M. A., Hashimoto, H., Milesi, C., and Myneni, R. B.: Variations in atmospheric $\mathrm{CO}_{2}$ growth rates coupled with tropical temperature, P. Natl. Acad. Sci. USA, 110, 13061-13066, https://doi.org/10.1073/pnas.1219683110, 2013.

Wang, X., Piao, S., Ciais, P., Friedlingstein, P., Myneni, R. B., Cox, P., Heimann, M., Miller, J., Peng, S., Wang, T., Yang, H., and Chen, A.: A two-fold increase of carbon cycle sensitivity to tropical temperature variations, Nature, 506, 212-215, 2014.

Watanabe, F., Uchino, O., Joo, Y., Aono, M., Higashijima, K., Hirano, Y., Tsuboi, K., and Suda, K.: Interannual variation of growth rate of atmospheric carbon dioxide concentration observed at the JMA's three monitoring stations: Large increase in concentration of atmospheric carbon dioxide in 1998, J. Meteorol. Soc. Jpn., 78, 673-682, 2000. 
Welp, L. R., Patra, P. K., Rödenbeck, C., Nemani, R., Bi, J., Piper, S. C., and Keeling, R. F.: Increasing summer net $\mathrm{CO}_{2}$ uptake in high northern ecosystems inferred from atmospheric inversions and comparisons to remote-sensing NDVI, Atmos. Chem. Phys., 16, 9047-9066, https://doi.org/10.5194/acp-16-9047-2016, 2016.
Worthy, D.: Canadian Baseline Program, Meteorological Service of Canada, Downsview, Ontario, 2003. 